\title{
Configuraciones de la migración femenina peruana en Iquique Chile, en el siglo XXI*
}

\author{
Menara Lube-Guizardi, Esteban Nazal, Felipe Valdebenito- \\ Tamborino y Eleonora López-Contreras
}

\author{
Universidad de Tarapacá, Chile, Universidad Alberto Hurtado, Chile, \\ Universidad de Chile, Chile
}

\section{Resumen}

Se presenta un estado del arte sobre la migración femenina peruana en Iquique (Región de Tarapacá, Chile). A través de la síntesis de investigaciones de corte cualitativo y cuantitativo, ofrecemos la contextualización de procesos sociales, económicos y políticos que facilitan la interpretación de los datos demográficos disponibles. Situaremos los límites geográficos, las características político-administrativas y ecológicas de Tarapacá y problematizaremos la noción de que la migración en Iquique es un fenómeno novedoso. Sintetizaremos las características económicas locales y su relación con las características sociodemográficas, la inserción laboral y las redes sociales de la población migrante peruana. Finalizamos el texto apuntando cómo se configuran los procesos identitarios nacionales y étnicos en Iquique, señalando las asimetrías y fricciones de la alteridad que se reproducen entre las peruanas y los locales chilenos.

Palabras clave: Migración femenina peruana, Iquique, configuraciones culturales, identidades, Chile.

\section{Abstract}

\section{Configurations of Peruvian Female Migration in Iquique (Chile) in the 21st Century}

The article presents a state-of-the-art of studies about the Peruvian female migration in Iquique (Region of Tarapacá, Chile). Through the synthesis of qualitative and quantitative research, we offer the contextualization of social, economic and political processes that endorses the interpretation of available demographic data. We will situate the geographical limits, the politicaladministrative and ecological characteristics of Tarapacá and will problematize the notion that the migration in Iquique is a novel phenomenon. We will synthesize the local economic characteristics and their relationship with the sociodemographic characteristics, the labor insertion and the social networks of the Peruvian migrant population. We conclude the text by pointing out how national and ethnic identity processes are configured in Iquique, stressing the reproduction of asymmetries and frictions of alterity between Peruvian woman and Chileans.

Key words: Female Peruvian Migration, Iquique, cultural configurations, identity, Chile.

* Agradecemos a la Comisión Nacional de Investigación Científica y Tecnológica de Chile (CONICYT) que financió el estudio a través del Proyecto Fondecyt 11121177. Agradecemos, además, a Arlene Muñóz, Grecia Dávila, Orlando Heredia y Tomás Greene quienes integraron el equipo de investigación. 


\section{INTRODUCCIÓN}

$\mathbf{E}$

1 presente artículo desarrolla una caracterización de Iquique como espacio de recepción de la migración femenina peruana, describiendo las problemáticas sociales vinculadas al fenómeno migratorio en la ciudad en la primera década del siglo XXI. ${ }^{1}$ Nuestros análisis derivan de la investigación del estado-del-arte de estudios cualitativos (historiográficos, sociológicos y antropológicos), contrastada con una síntesis propia de datos demográficos. Comprendemos que los desplazamientos de las migrantes peruanas integran circuitos migratorios en los que la relación entre movilidad y asentamiento es dinámica, enmarcándose en rutas que atraviesan Chile, Perú, Bolivia y Argentina (Guizardi y Garcés, 2013), pero apostamos por entender este proceso a partir de su grafía social específica en la capital de la Región de Tarapacá. ${ }^{2}$

Nuestro interés por estudiar la experiencia de las mujeres provenientes del Perú se relaciona con la compleja construcción de las fronteras, identidades y formaciones culturales nacionales chilenas y peruanas en este territorio ${ }^{3}$ desde su anexión por Chile en $1883 .{ }^{4}$ Pero también se vincula a la centralidad de las mujeres peruanas en la reproducción social de las familias y redes migrantes en Chile, en general, ${ }^{5}$ y en el norte chileno, en particular. $^{6}$

Siguiendo la reflexión sobre las contradicciones de las ideologías centralistas de las identidades nacionales en América Latina (Grimson y Guizardi, 2015), adherimos al desafío de replantear el papel del Norte Grande chileno en su propia constitución, comprendiéndolo en clave de alteridades nacionales históricas (Segato, 2007) que definen la relación entre peruanos

\footnotetext{
${ }^{1}$ Iquique se localiza en el Norte Grande de Chile, territorio situado sobre el Desierto de Atacama y compuesto por tres regiones político-administrativas chilenas: Arica y Parinacota (XV Región) con capital en Arica; Tarapacá (I Región) con capital en Iquique y Antofagasta (II Región), con capital en la ciudad de Antofagasta. Estas regiones fueron anexadas a Chile tras la Guerra del Pacífico (1879-1883). Los territorios de la I y XV Región pertenecían a Perú antes de la Guerra del Pacífico.

${ }^{2}$ Comprendemos que Iquique es un locus estratégicamente situado donde podemos observar la relación entre asentamiento y movilidad en las vidas de las mujeres peruanas: tanto entre Perú y Chile, como internamente en la región y entre ella y otras regiones chilenas. Gana (2014) y Katzman (2014) coinciden en esta apreciación en sus trabajos sobre la migración internacional en la ciudad.

${ }^{3}$ Ver: González Miranda (1994, 2002b, 2004, 2009); Tapia (2012); Tapia y Ramos (2013).

${ }^{4}$ Formalizada en el Tratado de Ancón, firmado entre Chile y Perú en 1883 (tras el término de la Guerra del Pacífico) (González Miranda, 2009:72, Tapia, 2012:.181; Valdebenito y Guizardi, 2014:37).

${ }^{5}$ Ver: Acosta (2011), Mora (2008), Setién y Acosta (2011), Stefoni (2009), Stefoni y Fernández (2011), Thayer (2011).

${ }^{6}$ Ver: Guizardi y Garcés (2012), Guizardi et al. (2014), Guizardi et al. (2015), Tapia y Ramos (2013), Valdebenito y Guizardi (2015).
} 
y chilenos. Contemplamos, además, la necesidad de superar ciertos nacionalismos metodológicos, resituando el papel histórico jugado por la expansión de Chile hacia el desierto en la construcción del paradigma étnico chileno (Guizardi y Garcés, 2014a).

Entender la migración femenina peruana que encontramos en Iquique actualmente, en su vinculación con procesos de larga duración que son centrales para las construcciones nacionales de Chile y Perú, plantea desafíos analíticos importantes, en los cuales la comprensión de la estructuración de los espacios de recepción migratoria se convierte en una necesidad crítica. Esto debido a que la configuración del contexto incide directamente en la experiencia de las situaciones sociales por parte de las mujeres peruanas, influenciando la relación entre sus prácticas, la estructura social, los procesos históricos de larga duración y las mediaciones simbólicas (Comaroff, 1985). Esta reflexión nos condujo a conceptualizar a Iquique como una configuración cultural, siguiendo el debate de Grimson (2011) en su esfuerzo por superar las lecturas antropológicas culturalistas y ahistóricas. ${ }^{7}$ Pensar en configuraciones culturales nos permite centralizar el contexto constructivo de las identidades sociales como parte de un campo de disputas que es político. Nos lleva a indagar en la cristalización de lo cultural como un elemento que, en el caso específico que nos atañe, particulariza los contenidos de las adscripciones identitarias nacionales chilenas y peruanas; y también los entendimientos acerca de la relación entre identidades étnicas y nacionales.

Es a partir de esta preocupación antropológica sobre los conflictos identitarios que reconstruimos en este artículo los aspectos políticos, nacionales, institucionales y económicos que configuran a Iquique como un escenario migratorio particular. Así, nuestra reconstrucción del contexto se operacionaliza desde un recorte analítico específico, centrado en aquellos fenómenos que impactan la adaptación situacional e identitaria de las migrantes peruanas. Esperamos contribuir tanto a la acumulación y sedimentación de elementos de análisis para los estudios migratorios en el Norte de Chile (Guizardi y Garcés, 2012), como a la consolidación de perspectivas interdisciplinarias sobre la realidad migrante.

\footnotetext{
${ }^{7}$ Hay cuatro dimensiones constitutivas de las configuraciones culturales. i) Ellas son campos de posibilidad: se refieren a las instituciones, representaciones y prácticas que, en determinado contexto son posibles, las que son imposibles, y aquellas que devienen hegemónicas (Grimson 2011:172). ii) Suponen que, en dado contexto, las acciones, formas de ser y enunciar las relaciones, experiencias y conocimientos guardan algún nivel de interrelación entre sí, pero sin derivar en una homogeneidad constitutiva. La configuración cultural sería, así, heterogénea y heterotópica (Grimson 2011:176). iii) Para ser articulada, ella requiere de una trama simbólica común. iv) Así, aun cuando asimétricamente, ella congrega elementos comunes y compartidos (Grimson 2011:177).
} 


\section{Particularidades geográficas, Limítrofes y POBlaCionales DE TARAPaCÁ}

"El desierto me ha sido infiel,// solo tierra, cascada y sal,/ piedra amarga de mi dolor,/ roca triste de sequedad". (L. Advis en Guerrero, 2007: 32).

Antes de la invasión española (a principios del siglo XVI), el territorio que configura actualmente a la región de Tarapacá sufrió distintas transformaciones, cobijando a diferentes diseños de límites y dimensiones espaciales, los cuales han dependido de las necesidades políticas y administrativas de los grupos sociales que ocuparon dicho espacio. Estas transiciones político-sociales intervinieron en la zona alterando, redistribuyendo y relocalizando los límites de ciudades, provincias, regiones y, más recientemente, las fronteras nacionales. Este activo proceso de redefinición de las disposiciones y límites entre grupos, poderes políticos y actividades económicas - que es, a la vez un proceso de invención de estos mismos límites - no ha cesado en la historia reciente de Tarapacá.

El poema de Luis Advis con que iniciamos este apartado parece presentarnos una interesante metáfora sobre las disposiciones territoriales de la región. Pareciera que el desierto ha sido infiel a las delimitaciones políticosociales y administrativas que por sobre esta región se cruzaron. Y esto porque todas y cada una de ellas fueron sucedidas por una forma política nueva que responde a la hegemonía de turno. La permanencia del desierto pareciera ser una contradicción a la transitoriedad de las construcciones limítrofes sobre él.

Metáforas poéticas aparte, la última de estas transformaciones ocurrió en 2007, cuando las provincias de Arica y Parinacota cambian de estatus y se transforman en Región. ${ }^{8}$ Si bien la separación de la Región de Arica y Parinacota significó que Tarapacá perdiera su condición de frontera con Perú hacia el norte, ésta mantiene límites con Bolivia en al Este ${ }^{9}$, y sigue siendo un polo de atracción de migrantes internacionales: tanto de peruanos como de bolivianos (Garcés y Moraga, 2015; Tapia y Ramos, 2013).

En la actualidad, Tarapacá limita al norte con la XV Región de Arica y Parinacota, al sur con la II Región de Antofagasta. Desde 2007, la Región de Tarapacá posee una superficie de $42225.8 \mathrm{~km}^{2}$, siendo la sexta región más grande del país, lo que la posiciona por encima de Arica (con 16873

\footnotetext{
${ }^{8}$ Mediante la promulgación de la Ley № 20.175 se creó la XV Región de Arica y Parinacota, separando ambas provincias de la Región de Tarapacá (Congreso Nacional de Chile, 2007) y provocando la escisión del histórico espacio Tarapaqueño que fue traspasado de Perú a Chile en el siglo XIX (Valdebenito y Guizardi 2014:282).

${ }^{9}$ Hay tres pasos fronterizos formalmente habilitados entre Chile y Bolivia en la Región de Tarapacá: Colchane, Hito Casón y Jama (Ministerio del Interior y Seguridad Pública, 2015).
} 
$\mathrm{km}^{2}$ aproximadamente), pero por debajo de Antofagasta (con $126049 \mathrm{~km}^{2}$, aproximadamente).${ }^{10}$ La Figura 1 representa a estas tres regiones que configuran el Norte Grande chileno, sus ciudades más relevantes, las fronteras regionales e internacionales.

En la Región se encuentra la provincia de Iquique, que alberga la comuna de Iquique (con unos 186 mil habitantes) y, al noreste de ésta, la comuna de Alto Hospicio (con unos 76854 habitantes) (Compañía Minera Doña Inés de Collahuasi, 2008). Al norte de la Provincia de Iquique se localiza la Provincia del Tamarugal, compuesta por las comunas de Pozo Almonte (14 950 habitantes), Pica (12 907 habitantes), Colchane (1 649 habitantes), Huara (3 095 habitantes) y Camiña (1 167 habitantes). Según las proyecciones realizadas por el Instituto Nacional de Estadísticas, hacia $2013^{11}$ la población de la región sería de 338 mil habitantes (INE, 2014b). La dinámica de asentamiento humano destaca por altas concentraciones en la capital Iquique, donde se encuentra 55 por ciento de la población regional.

Esta concentración en la capital es un fenómeno que se puede observar como progresivo en el tiempo. Entre 1992 y 2012, Iquique aumentó su población en 21.9 por ciento, mientras que otras comunas como Colchane y Camiña mostraron un crecimiento negativo (INE, 2014b). Esto se explica principalmente por los procesos de transformación del ámbito productivo de los valles y del altiplano, con la instalación de las faenas mineras durante las últimas décadas y la presión que ejercen sobre la organización y actividad productiva indígena. La migración y urbanización de la población indígena del altiplano y de la pampa, como argumentan los estudios sobre los grupos sociales aymara en el norte de Chile (Bärh, 1980; Gundermann y González, 2008, Gundermman y Vergara, 2009), es un proceso vinculado a las ideologías y políticas estatales desarrollistas y urbanizadoras, y se viene dando desde mediados del Siglo XX (Valdebenito y Guizardi, 2014).

Por otro lado, la comuna que en proporción experimentó un mayor aumento demográfico durante los últimos años es Alto Hospicio, que registró un incremento poblacional de 1590.3 por ciento desde su creación en 2004.

\footnotetext{
${ }^{10}$ A pesar de ser una región de gran envergadura, esto contrasta con la distribución poblacional, que como se señala más adelante, se concentra principalmente en lo que se conoce como "el Gran Iquique".

${ }^{11}$ Uno de los principales problemas para la actualización de antecedentes demográficos sobre la región es el cuestionamiento de la aplicación del Censo chileno de 2012. Los informes más recientes suelen utilizar proyecciones realizadas a partir del Censo 2002 o las estimaciones derivadas de las Encuestas de Caracterización Socioeconómica de Chile (CASEN) de 2011 y 2013. Asimismo, hay que considerar que las metodologías del Censos y de la CASEN no están adaptadas a captar las experiencias de poblaciones en movimiento. El uso prudente de estos instrumentos en estudios de poblaciones migrantes requiere asumirlos como estimaciones referenciales.
} 
Figura 1: Norte Grande de Chile. División regional actual, ciudades importantes y fronteras internacionales

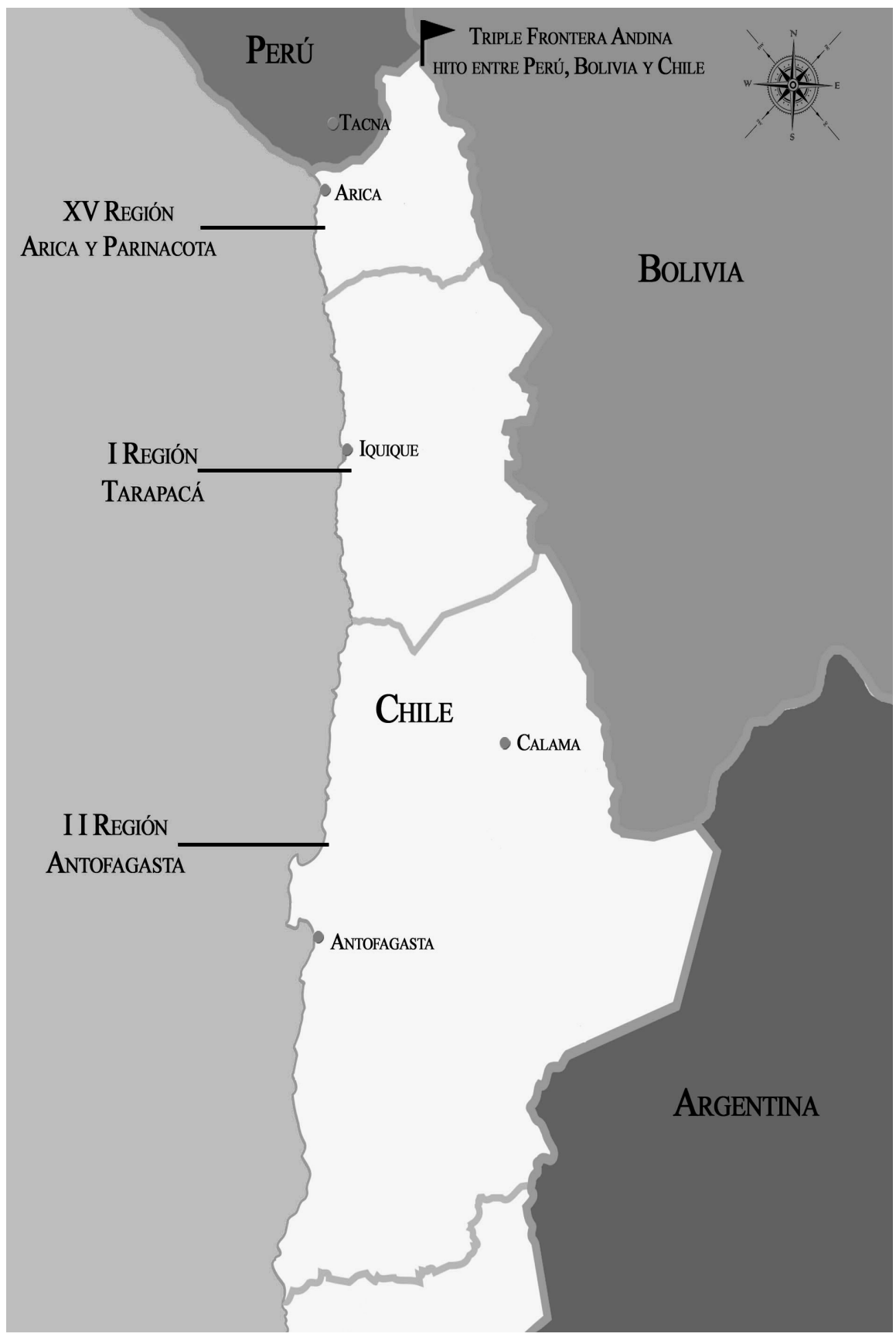

Fuente: elaboración de Paola Salgado. Proyecto Fondecyt 11121177. 
Su autonomía como comuna (antes pertenecía a la comuna de Iquique) es el reconocimiento de su papel urbano en la consecución de una solución habitacional ante el aumento de población en la capital y la llegada de distintos grupos migrantes (INE, 2014a). La densidad de las relaciones entre ambas comunas supone una unidad territorial conocida como "El Gran Iquique". Debido a los desplazamientos de población, esta unidad concentraba en 2012 a unos 279408 habitantes, lo que equivale a más de 90 por ciento de la población total de la Región (Guerrero, 2014). En síntesis, la distribución poblacional en el territorio de Tarapacá se presenta como discontinua, con centros bien definidos y que responden a las distintas actividades económicas de la región (CIPTAR, 2012). Este patrón de asentamiento poblacional afecta, lógicamente, las disposiciones territoriales de la población migrante que llega a Tarapacá.

Sobre la composición de los habitantes, los datos de masculinidad, edad de la población y relación urbano/rural al año 2002 son similares a los del país (Compañía Minera Doña Inés de Collahuasi, 2008). El porcentaje de población masculina es de 51.5 por ciento y el de personas que viven en sectores urbanos es de 94.8 por ciento. En comparación, el índice de mujeres entre los migrantes peruanos en Tarapacá es superior a 50 por ciento, de forma que el patrón de feminización de la migración peruana va a contracorriente del patrón de masculinización poblacional de la región de Tarapacá.

Sobre el indicador de concentración urbana de la población, cabe señalar dos cosas: i) la población migrante acompaña este patrón (mayor concentración en espacios urbanos); ii) la mantención de los porcentajes de urbanización poblacional durante los últimos años no significa que no se hayan presentado movimientos humanos importantes entre la ciudad y los sectores rurales (Garcés y Moraga, 2015). En efecto, debido a las presiones de la actividad minera se producen despoblamientos y repoblamientos de sectores rurales y urbanos, así como la creación de nuevos asentamientos que permiten acercar a los trabajadores a las faenas (Garcés y Moraga, 2015; Guerrero, 2014). Los migrantes son parte activa de este movimiento.

En el Censo 2002, 8.2 por ciento de los habitantes (19 400 personas) declaró pertenecer a algún grupo indígena, lo que representa casi el doble del promedio nacional chileno (de 4.5 por ciento). Más de tres cuartas parte de la población que se declaró indígena ( 77 por ciento) se identificó con grupos aymara. En estos dos aspectos, la población migrante peruana acompaña al patrón poblacional general de la región. Más allá de las claras insuficiencias del censo en su ejercicio de conteo de la población indígena 
en Chile (Gundermann y Foerster, 2005), estos datos relevan consideraciones importantes. La presencia de los aymara en Tarapacá es significativa, por al menos tres cuestiones. i) Representa una continuidad debido a que este territorio es, históricamente, el espacio social de grupos sociales de esta etnia. ii) Porque la región de Tarapacá, incluso con las distorsiones del censo, concentraría cerca de 31 por ciento de la población aymara chilena. iii) Porque 60 por ciento de los aymara se concentran en las comunas de Iquique y Alto Hospicio, pero su presencia es más notoria que en el resto de las comunas, debido a la baja concentración en ellas de población autodeclarada no-indígena (Compañía Minera Doña Inés de Collahuasi, 2008).

En la región, la población indígena se incrementó en 8800 personas entre los censos 1992 y 2002. Entre las razones que nos permiten comprender este aumento se encuentra que Chile protagoniza, desde hace veinte años, procesos importantes de reafirmación étnica y etnogénesis (Dittmar, 1996; Gundermann, 2013; Hidalgo Vallejos, 2004), con un incremento de las poblaciones que asumen su condición indígena y la enuncian abiertamente. Además, el aumento de población aymara en Iquique y en Tarapacá también se debe a la migración internacional.

\section{CONFIGURACIONES ACTUALES DE UNA MOVILIDAD DE LARGA DURACIÓN}

La historia de lo que hoy entendemos como la Región chilena de Tarapacá y de su capital, Iquique, estuvo intermitentemente atravesada -a lo largo de los últimos siglos - por manifestaciones muy peculiares de la relación entre asentamiento y movilidad poblacional. Este territorio fue atravesado también, por prácticas humanas de movilidad que, en gran medida, desafían las nociones "sedentario-céntricas" (Sutcliffe, 1996) sobre la experiencia social del espacio. A contracorriente de la idea hegemónica que naturaliza el sedentarismo como forma sine qua non de ocupación territorial, innumerables estudios históricos y arqueológicos han sentado precedentes sobre una compleja relación entre moverse y asentarse en los territorios surandinos del Atacama, cuestión que dialoga con las particularidades ecológicas y orográficas de esta región y, por supuesto, las limitaciones y posibilidades que ellas implican.

Revisando las investigaciones sobre los modos de vida en el sur del Atacama en los últimos seis siglos, nos encontramos con trabajos como los de Adán et al. (2007), Núñez y Dillehay (1979), Núñez y Nielsen (2011), que nos hablan de un modo de vida pre-incaico en esta zona (entre los Siglos XV e inicios del XVI) marcado por prácticas de caravaneo, con sistemas de movilidades que Núñez y Dillehay (1979) denominan "giratorias", 
con el desplazamiento de los grupos sociales de la costa a la cordillera y altiplano de forma estacional. ${ }^{12}$

La expansión incaica sobre este territorio, en la primera mitad del siglo XVI, impactó este sistema de movilidades, con el establecimiento de ciertas nociones de urbanidad propias de la élite incaica, las cuales forjaron otro sentido de organización de las movilidades entre asentamientos, con una centralización de los recursos en la formación de espacios urbanos (Urbina, 2011; Urbina, 2014). La administración imperial jerarquizó y segregó las densidades poblacionales y la urbanización en el sur andino, por lo que la estructura que el imperio desplegó allí se considera como discontinua, heterogénea y segmentada (Sanhueza, 2008: 59). Se visualizaba un recorte territorial dibujado a modo de mosaico, con distintas dimensiones y formas, las cuales dependían tanto de la importancia política como del interés en los recursos de cada zona. Esto, lógicamente, reorganizó la relación entre asentamiento y movilidad en el desierto, pero a partir de lógicas ya no necesariamente (o estrictamente) vinculadas a los modos de vida grupales locales en la actual región de Tarapacá.

En el siglo XVI, la invasión española sobre estos territorios implicaría otra presión hacia la sedentarización de las poblaciones, con una centralización de las ciudades portuarias en la costa del pacífico. No obstante, el trajín de la plata desde las minas del entonces Alto Perú (hoy Bolivia) y los plantíos y comercio de productos agrícolas y ganaderos del altiplano se mantendrían como un sistema comercial de movilidades sociales entre las plataformas del desierto. Con las independencias nacionales del Siglo XIX, el territorio pasa a pertenecer a la República peruana, lo que coincide con la implementación de la macro economía extractivista del salitre en la zona. El ciclo del salitre demandó una cantidad ingente de mano de obra, intensificando las migraciones de bolivianos, peruanos, chilenos, europeos y asiáticos hacia Tarapacá (González Miranda, 2002a, 2008b, 2009; González Pizarro, 2009; Tapia, 2012, 2013).

A fines del Siglo XIX, la Guerra del Pacífico y la posterior anexión del territorio tarapaqueño por parte de Chile incidirían una vez más en la relación entre movilidad y permanencia en estos espacios, complejizando con nuevas etiquetas identitarias nacionales la constitución de la relación entre espacio y pertenencia social. El proceso de chilenización sobre estos territorios se hizo acompañar de una política desarrollista y de urbanización (ya a inicios del Siglo XX), que preconizó incentivar la migración

${ }^{12}$ Este fenómeno habría tenido un especial impacto en el establecimiento de alianzas y conflictos entre los grupos en las diferentes plataformas del desierto, constituyendo los sistemas de prestación total (Mauss, 1979) desarrollados por estos colectivos. 
desde el altiplano a las ciudades de la costa, un movimiento humano muy intenso en toda la primera mitad del siglo XX (Bärh, 1980). Esta migración se relaciónó con la noción que chilenizar a los habitantes de la pampa y del altiplano era equivalente a desindigenizarlos y urbanizarlos (Valdebenito y Guizardi, 2014). El proceso alteró los modos de organización y experiencia social del espacio entre las poblaciones indígenas locales (predominantemente aymara); pero sería equivocado pensar que las históricas lógicas de movilidad indígena entre las ciudades de la costa (en especial Iquique) y las localidades de la pampa y del altiplano hayan cesado de existir (Gundermman y González, 2008; Gundermann y Vergara, 2009; Vergara y Gundermann, 2007). También constituiría una equivocación pensar que estos movimientos se hubieran limitado a espacios confinados al territorio chileno, dado que buena parte de los circuitos de movilidad sobre este territorio reincorporan rutas anteriores al establecimiento de estas fronteras (Tapia, 2013; Tapia y Ovando, 2013). Caminos que se cruzan hacia Perú, Bolivia y Argentina (Guizardi y Garcés, 2013).

La migración en Tarapacá no es, por lo tanto, un fenómeno novedoso. Pero novedosas serán, en todo caso, las configuraciones culturales que estas movilidades desarrollan en el siglo XXI. ¿Cómo podemos situar esta actual configuración de movilidades en la zona?

En la actualidad, la región se encuentra en un nuevo proceso de incremento de la población migrante vinculado a cuatro elementos macrosociales. Por un lado, están las tendencias globales a la intensificación de los flujos humanos que se verifican especialmente tras la generalización de la lógica de globalización desde los años 90 en todo el mundo (Castles y Miller, 2004). En segundo lugar, la intensificación de la migración intrarregional latinoamericana, misma que establece nuevos destinos migratorios, debido en gran medida a las dificultades documentales impuestas por países desarrollados desde 2001 (Mora, 2008; Stefoni, 2002). Como tercer elemento se encuentra la inestabilidad económica que atraviesa Argentina, país que es el principal destino de la migración intra-regional sudamericana (Guizardi y Garcés, 2013). Esto motivó que migrantes peruanos y bolivianos que cruzaban el Norte Grande en dirección al país transandino optaran por intentar quedarse en las ciudades mineras que están en la ruta de este circuito migrante. Finalmente, hay que considerar los procesos sociales, económicos y políticos vividos por Chile y que han tenido un impacto muy particular en los espacios del Norte Grande en los últimos años: el incremento de las inversiones y el boom productivo de la economía minera chilena desde 1990 (Carrasco y Vega, 2011), la redemocratiza- 
ción y la lenta apertura del país a los acuerdos regionales que potencian la circulación de personas.

Cuando pensamos en cómo estos procesos macrosociales impactan a las configuraciones de la migración en el contexto iquiqueño nos encontramos con cuatro elementos importantes a destacar. En primer lugar, habría que enfatizar que Tarapacá es una zona rica en recursos mineros y con puertos privilegiados. Sin embargo, el entorno natural, caracterizado por la falta de recursos hídricos, así como constantes fenómenos sísmicos, para los cuales no siempre se cuenta con la infraestructura estatal adecuada, profundizan la vulnerabilidad de los sectores marginales. Esto se expresa, por ejemplo, cuando la competencia por el uso del agua tensiona la instalación de proyectos mineros y termoeléctricos frente a las economías agrícolas locales.

Asimismo, la región tiene una acentuada historia de desigualdades sociales, con el predominio, en la instauración de procesos de capitalismo extractivista minero (desde fines del Siglo XIX en adelante), de violencias sociales de diversas escalas. Estas desigualdades sociales han sido fuertemente combatidas por el movimiento obrero organizado en Iquique, que recibió violentas respuestas estatales y empresariales (González, 2007). La dura represión que estos obreros sufrieron repercutió en el desarrollo del movimiento obrero en todo Chile, pero también en ofensivas desde el Estado chileno para desarticular la identidad sindical en esta zona, la cual se caracterizaba por aunar a trabajadores chilenos, peruanos y bolivianos bajo luchas sociales comunes (González, 2007). ${ }^{13}$ Estas ofensivas, intensificadas en la dictadura militar de Augusto Pinochet, actuarán para impedir y romper cualquier lógica identitaria que vinculara a la experiencia laboral por sobre la nacionalidad, generando tensiones y oposiciones entre obreros chilenos, peruanos y bolivianos.

Por otro lado, al ser una zona de frontera, al constituirse como un márgen del proyecto de construcción de la nación chilena (Guizardi y Garcés, 2014a; Tapia y Ovando, 2013; Tapia y Parella, 2015), la presencia y ausencia del Estado en Tarapacá se presentan como una contradicción constante. Ésta se manifiesta a medio camino entre la instalación permanente de símbolos patrios (en su excesiva enunciación y performance en los espacios públicos) y la simultánea carencia de infraestructuras urbanas, de salud, de educación y sociales en general por parte del Estado. Esta particular y contradictoria ausencia en la presencia, se configura como una carencia de regulaciones y de apoyo a la ciudadanía. Y se refleja, a veces a modo de

${ }^{13}$ Como las huelgas salitreras reprimidas por el Estado con la matanza de la Escuela de Santa María (1907). 
convulsión social, en los conflictos contra los grandes proyectos mineros y termoeléctricos, que sí reciben las inversiones estatales en la potenciación, por ejemplo, de infraestructuras de transporte y productivas.

En cuarto lugar, el impacto de la minería cuprífera ha generado un aumento en los indicadores macroeconómicos, como el PIB, en la región de Tarapacá (Carrasco y Vega 2011). Pero los beneficios de este aumento se hacen sentir por la población general como escasos, fugases y localizados (Guerrero, 2014), debido a que se reproducen patrones muy acentuados de concentración del excedente económico. Así, si los espacios urbanos de Iquique y sus habitantes vinculados a los proyectos mineros se ven beneficiados con altos salarios, estos efectos no son del todo notorios en el resto de la región. La economía minera se presenta a los trabajadores que se desplazan a Iquique (sean ellos chilenos, peruanos o bolivianos) como una promesa de acumulación económica que no siempre se cumple. En todo caso, la manifestación social de estos beneficios es siempre más notoria en el espacio urbano, consolidando un patrón de desigualdad entre la ciudad y los pueblos de la pampa y del altiplano.

En síntesis, Tarapacá se constituye como un polo de atracción migrante atravesado por un contexto de conflictos sociales, asimetrías de infraestructura, concentración urbana y carencia de servicios. Todo esto configura la forma cómo se mira a los nuevos migrantes, no en pocas ocasiones, asociándose su presencia con el aumento de la saturación de los servicios públicos (sanitarios, de vivienda, educacionales). El fenómeno se entrecruza con los imaginarios sobre la otredad peruana y boliviana, en un panorama que complejiza las representaciones sociales sobre esta migración. Antes de entrar en este tema, entregaremos más detalles sobre las particularidades económicas de la región.

\section{CONTEXTOS ECONÓMICOS Y PROCESOS DE MOVILIDAD POBLACIONAL}

En la actualidad, la economía de Tarapacá se caracteriza por la inversión transnacional dirigida a la productividad cuprífera y las ventajas comerciales producidas por la Zona Franca de Iquique (ZOFRI). ${ }^{14}$ Como señala el Centro de Investigación en Políticas Públicas de Tarapacá (CIPTAR, 2012), ambos elementos son el reflejo de la forma económica histórica de la región. El desarrollo comercial se vincula al puerto (en Iquique), mientras que en el interior de la pampa se concentra la actividad minera

\footnotetext{
${ }^{14}$ Según Vicuña et al. (2015: 38): "la ciudad de Iquique, capital de la I Región, adquirió en 1975 - mediante el Decreto Fuerza Ley (DFL) 341 - franquicias aduaneras, pasando su puerto a ser una Zona Franca: estatus del que entre 1953 y 1963 había gozado Arica (Estrada, 2010)”.
} 
(plata, salitre y cobre). En ambos casos, son actividades orientadas a la exportación.

El nuevo Gran Ciclo Minero (CIPTAR, 2012), iniciado en la década de 1980 y consolidado en la década de 1990, se centra en metales cupríferos y es uno de los principales aportes al Producto Interno Bruto (PBI) de Chile (Carrasco y Vega, 2011). A finales de los 90, mientras el ciclo pesquero e industrial se difuminaba, reduciendo su participación en el PIB regional a tres y siete por ciento respectivamente, la minería logró consolidarse en 35 por ciento del PIB de Tarapacá, ${ }^{15}$ mientras que el comercio alcanzó 17 por ciento (CIPTAR, 2012). Actualmente la minería influye marcadamente en el Indicador de Actividad Económica Regional (INACER) ${ }^{16}$ y la baja productividad de la faena arrastra el decrecimiento de la zona y otros sectores productivos (INE, 2014a).

La ZOFRI, por otro lado, responde en su origen al Plan de desarrollo económico instaurado en la dictadura militar(1973-1989) para la región, y que trasladó los beneficios económicos, comerciales e industriales desde la ciudad de Arica a Iquique, situación que generó conflictos interregionales con la primera.

Las diferencias entre la producción minera y el resto de las actividades marcan también brechas en los salarios. CIPTAR (2012) registra en 2007 que las diferencias entre los ingresos medios de un trabajador de la minería y uno en la agricultura es de una razón de 3.6 a $1 .{ }^{17}$ De la misma forma, otros cuatro sectores o ramas económicas (o sea, 66 por ciento de los trabajadores de la región) poseen salarios en promedio por debajo de la media regional. Si consideramos que el comercio es la actividad que genera mayor cantidad de empleos y que además es una de las que presenta los salarios medios más bajos (229 903 pesos chilenos mensuales) (CIPTAR, 2012: 37), es posible dar cuenta del impacto de la minería en la estructura social tarapaqueña. Si bien el PIB per cápita es de los más altos a nivel nacional (el segundo después del de la Región de Antofagasta), Tarapacá presenta una situación económica poblacional deteriorada en comparación con el incremento productivo experimentado desde 1990 (CIPTAR, 2012). ${ }^{18}$

\footnotetext{
${ }^{15}$ En la primera década del siglo XXI la venta del cobre comprendía 83 por ciento de las exportaciones regionales, y 10.5 por ciento de las nacionales (CIPTAR, 2012: 21).

${ }^{16}$ El INACER es un instrumento que tiene como base el Producto Interno Bruto y permite visualizar junto con otros indicadores (como el mismo PIB) el peso de las áreas productivas en la producción agregada a nivel regional o nacional (INE, 2010).

${ }^{17}$ En el caso de la minería, el sueldo medio mensual es de 677012 pesos chilenos, mientras que los trabajadores de la agricultura este indicador es de unos \$186 922 (CIPTAR, 2012).

${ }^{18}$ Esta realidad incide en los elevados niveles de pobreza y marginación social. En Tarapacá, las personas en situación de pobreza representaban 11.8 por ciento en $2006,15.8$ por ciento en 2009 y 13.1 por ciento en 2011 (Ministerio de Desarrollo Social, 2013). La pobreza se encuentra más marcada en los sectores rurales y de difícil acceso en la pampa y el altiplano.
} 
Las principales ramas productivas por número de ocupados corresponden a la actividad Comercial (18.73 por ciento) y la minería (10.57 por ciento), ${ }^{19}$ seguido de cerca de actividades como la construcción (diez por ciento), la enseñanza ( 9.22 por ciento) o el transporte y las comunicaciones (9.2 por ciento) (INE, 2015). La tasa de desocupación alcanzó siete por ciento a finales de 2014, porcentaje superior al promedio nacional de 6.2. ${ }^{20}$

Cabe señalar que este desarrollo económico comercial y minero que describimos aquí tuvo por efecto una expansión urbana, incrementando la necesidad de mano de obra en la construcción. Asimismo, prospera el comercio a pequeña escala entre Iquique y Tacna, la ciudad peruana más cercana a la frontera con Chile, así como también el contrabando a pequeña y larga escala entre localidades del sur peruano y de Tarapacá (Berganza y Cerna, 2011: 135).

En conjunto, estas condiciones económicas generaron situaciones atractivas para los migrantes en general (Vergara, 2005; Tapia, 2012; Berganza y Cerna, 2011). No obstante, inciden aspectos de género que influyen en la inserción específica de las mujeres peruanas migrantes. Por un lado, la minería constituye un universo laboral masculinizado: abriendo nichos de trabajos donde las mujeres tienen, hasta la actualidad, una empleabilidad muy limitada. Ellas desarrollan funciones "complementarias" en las minas: limpian los campamentos y cocinan, por ejemplo. En efecto, la principal actividad económica, aquella que deriva en los más elevados niveles de sueldo en Tarapacá, resulta ser centralmente masculina, lo que incide en la realidad económica de las migrantes y en los contornos generales del mercado laboral femenino.

Por otro lado, la importancia de la ZOFRI como dinamizadora de los flujos comerciales en territorio chileno, en espacios del sur del Perú y del noroeste boliviano (Garcés y Moraga, 2015), también condicionan especificidades de género en la inserción de las mujeres peruanas. El comercio y el contrabando a través de las rutas andinas entre territorios chilenos, peruanos y bolivianos son actividades en las que las mujeres aymara (de estas tres nacionalidades) tienen protagonismo (Guizardi et al., 2014). El papel de las mujeres peruanas aymara en el comercio y contrabando a pequeña escala entre el sur del Perú, la ciudad de Arica y la ZOFRI, constituye un fenómeno de movilidad transfronteriza y circular que impulsa la presencia

\footnotetext{
${ }^{19}$ Las faenas mineras necesitan de una cantidad limitada de trabajadores para desarrollarse. Esto se observa en proyectos cupríferos denominados de Gran Minería tales como Cerro Colorado, Quebrada Blanca y Doña Inés de Collahuasi, los cuales a pesar de su importante peso productivo en la región "no sobrepasan en promedio 500 trabajadores cada una" (Guerrero, 2014: 223-224). ${ }^{20}$ Tarapacá es la cuarta región en el ranking de las tasas de desocupación en Chile.
} 
de mujeres peruanas en Iquique. Mientras la minería constituye un nicho laboral donde el protagonismo masculino es innegable, el comercio (que la ZOFRI dinamiza) constituye un polo de atracción de mujeres peruanas aymara.

\section{CARACTERIZACión DEMOGRÁFICA DE LA MigRaCión PERUANA EN TARAPACÁ Y EN IQUIQUE ${ }^{21}$}

\section{Panorama general de la presencia peruana en Tarapacá}

La migración internacional peruana experimentó un importante incremento desde 2001. Si para este año la cantidad de peruanos que emigró totalizó poco más de 60 mil personas, en 2009 esta cifra alcanzaba las 2038 107, lo que correspondía a siete por ciento del total de habitantes de Perú (OIM, 2013a). Los principales destinos de esta migración en la última década son Estados Unidos (48.1 por ciento), España (10.6 por ciento), Italia ( 7.9 por ciento), Argentina (6.3 por ciento), Venezuela (4.7 por ciento), Japón (4.6 por ciento) y Canadá (2.4 por ciento) (OIM, 2013a).

Chile, desde inicios de la década de 1990, presenta un aumento de la población migrante, especialmente de origen peruano (Araujo, Legua y Ossandón, 2002: 6-8; Erazo, 2009; Godoy, 2007: 42; Jensen, 2009: 106; Lipszyc, 2004: 11, Martínez, 2003: 1 y Martínez, 2005:109; Navarrete, 2007: 179; Núñez y Hoper, 2005: 291; Núñez y Torres, 2007: 7; Poblete, 2006: 184; Santander, 2006: 2; Schiappacasse, 2008: 23 y Stefoni, 2005: 283-284). ${ }^{22}$ Esto se verifica con los datos de los Censos 1992 y 2002 y de la CASEN, pero también mediante el conteo de visas de residencia otorgadas a extranjeros por el Ministerio del Interior chileno. Se observa un creci-

\footnotetext{
${ }^{21}$ Los datos que presentamos en las tablas de este apartado son de elaboración propia con base a los censos 1992 y 2002 disponibles en la página del Instituto Nacional de Estadísticas de Chile. Reagrupamos las informaciones de cada una de las comunas que después de la creación de la Región de Arica y Parinacota, en 2007, permanecieron en la Región de Tarapacá: Cuando especificamos los datos de esta región en las tablas, lo hacemos a partir de recopilar las informaciones de las comunas de Iquique, Pica, Pozo Almonte y Huara. Para 1992 y 2002, la actual comuna tarapaqueña de Alto Hospicio aún no se había autonomizado, lo que ocurrió en 2004. Las informaciones sobre esta comuna integran, por lo tanto, los datos de la comuna de Iquique. Las cifras que presentamos como referentes a la Región de Arica y Parinacota devienen de la compilación de los datos demográficos de las comunas de Arica, Camarones, Putre y General Lagos que en 1992 y 2002 integraban aún la antigua Región de Tarapacá.

${ }^{22}$ Se produce en Chile una percepción social muy distendida de que el fenómeno equivaldría a una especie de "invasión". Esto se debe a los imaginarios sociales en relación las identidades peruanas y chilenas; habiendo un fuerte rechazo a la presencia peruana (Tijoux, 2007; 2011; 2013). A su vez, los migrantes argentinos en Chile constituyeron el colectivo nacional más relevante en el país desde 1990 y hasta inicios del siglo XXI (Guizardi y Garcés, 2012). Pero esta migración nunca fue entendida como una invasión o un tema relevante de estudios (Grimson y Guizardi, 2015; Jensen, 2014).
} 
miento constante de éstas, pasando de 18324 en 2000, a 76.335 en 2011 (Contreras, Ruiz-Tagle y Sepúlveda, 2013: 6).

Las localidades de destino preferidas de esta migración son áreas con un crecimiento económico importante: la Región Metropolitana de Santiago y los sectores mineros del norte (Contreras, Ruiz-Tagle y Sepúlveda, 2013: 22; Tapia, 2012: 186). Según los datos del Censo de 2002, 64.81 por ciento de los migrantes en Chile radica en Santiago (DEM, 2010: 15). Pero la capital agrupa alrededor de 40 por ciento de la población del país, de forma que los migrantes componían 3.35 por ciento del total de personas viviendo ahí (DEM, 2010: 16). En el norte del país, en las Regiones de Tarapacá, Arica y Parinacota y Antofagasta los migrantes constituían, respectivamente, 6.66 por ciento, 6.1 y 3.7 por ciento de la población local, también según el Censo 2002 (DEM, 2010: 16-17).

Como hemos señalado anteriormente, Tarapacá registra un constante movimiento de poblaciones desde la colonia. El contexto de violencia simbólica y física durante el proceso de chilenización, que incidió en la expulsión forzada de peruanos del territorio chileno, no impidió la reincidencia de tránsitos y flujos migratorios durante el siglo XX (Tapia, 2012; Tapia y Ramos, 2013). No obstante, se observan claramente dos hitos relacionados con la presencia extranjera en estos territorios: en el periodo del boom Salitrero entre finales de la Guerra del Pacífico (1883) y la década de 1930 y a comienzos de la década de 1990 (Tapia, 2012: 181).

En términos de concentración de población extranjera en Tarapacá, el periodo posterior a la Guerra del Pacífico presenta las cifras más elevadas para la historia de la región desde su anexión por Chile hasta la actualidad. Esto se refiere al hecho de que la población peruana que residía en este territorio pasó a ser considerada extranjera: migrantes que no emigraron. Tras el conflicto, el porcentaje de migrantes internacionales alcanzaba alrededor de 51.9 por ciento de la población, cifra que disminuiría dramáticamente a 12 por ciento en finales de 1930 (producto de la nacionalización y expulsión de extranjeros) (Tapia, 2012). En la década de 1940, con la crisis del precio del salitre y el cierre de las salitreras, comienza el masivo desplazamiento de población desde el norte hacia el sur de Chile. Los migrantes se limitan a 6.8 por ciento de la población regional (Tapia, 2012).

Pero el porcentaje más bajo de población migrante en Tarapacá, de 1.8 por ciento, sucede en $1992 .{ }^{23}$ Desde ese momento hasta la actualidad, la

\footnotetext{
${ }^{23}$ A principios de la década de 1990, la demanda de mano de obra migrante peruana en Tarapacá se concentró en dos tipos: por un lado, una esporádica relacionada con el comercio que unía Iquique con la ciudad de Tacna y, en segundo lugar, una permanente relacionada con empleos calificados (como el ensamblaje de automóviles) (Berganza y Cerna, 2011). Se distinguen así
} 
proporción de migrantes comienza a aumentar: en 2002 se registra tres por ciento y en 2012 siete por ciento (Tapia, 2012).

Como ilustra la Tabla 1, el incremento de la población migrante de los cinco colectivos nacionales más numerosos es innegable. No obstante, el colectivo peruano es el que presenta un incremento más expresivo, pasando de 370 a 2642 personas entre 1992 y 2002. Estas tendencias al alza de la población peruana en Tarapacá se habrían mantenido también para el periodo entre 2002 y 2012, superando el incremento del colectivo boliviano, que sería el segundo más numeroso en la región. ${ }^{24}$ Como señala Tapia (2012: 186), "según los datos de 2002, los peruanos aumentaron en 79 por ciento respecto del año 1992 y los bolivianos 42 por ciento respecto al mismo año". Entre 2002 y 2012, aún según Tapia (2013), a partir de los datos del Censo 2012, habría ocurrido un incremento en la migración peruana y boliviana en las regiones fronterizas de Arica y Parinacota y Tarapacá. Estos datos reflejarían que, en la Región de Tarapacá, alrededor de unas 17 232 personas serían migrantes peruanos o bolivianos, lo que corresponde al 77 por ciento de la totalidad de extranjeros en la zona. De estos, 48 por ciento serían peruanos (Tapia, 2013: 233).

Tabla 1: Cinco nacionalidades de extranjeros más numerosas en Tarapacá 1992 y 2002 . Valores absolutos según sexo

\begin{tabular}{lrrrrrrr}
\hline & \multicolumn{9}{c}{ Sexo del encuestado } & & \\
\cline { 2 - 6 } País de & \multicolumn{2}{c}{ Hombres } & \multicolumn{2}{c}{ Mujeres } & & \\
nacimiento & 1992 & 2002 & 1992 & 2002 & Total 1992 & Total 2002 \\
\hline Bolivia & 279 & 865 & 328 & 1066 & 607 & 1931 \\
Perú & 222 & 1091 & 148 & 1551 & 370 & 2642 \\
Argentina & 138 & 209 & 114 & 207 & 252 & 416 \\
Ecuador & 16 & 127 & 31 & 204 & 47 & 331 \\
China & 73 & 161 & 47 & 112 & 120 & 273 \\
\hline
\end{tabular}

Fuente: elaboración propia con base en los datos de los censos 1992 y 2002, disponibles en la web del Instituto Nacional de Estadísticas de Chile.

Los migrantes peruanos (a ejemplo de lo que también ocurre para los bolivianos y argentinos) son caracterizados a partir de las encuestas censales de 1992 y 2002 como englobados entre franjas de edad que van pre-

dos oleadas de movilización a principios de la década: la primera relacionada con el comercio, la segunda con la industria.

${ }^{24}$ En la zona norte de Chile peruanos y bolivianos fueron mayoría entre la población migrante internacional, pero sus proporciones variaban claramente de ciudad a ciudad. En Arica, los censos de 1992 y 2002 mostraron una concentración mayor de bolivianos, mientras que en Iquique la situación se sucedía con ciudadanos peruanos (Tapia, 2012). 
dominantemente de los 18 a 50 años (Guizardi y Garcés, 2012), constituyendo población en edad económicamente activa. La Tabla 2 detalla estos datos ilustrando las franjas de edad de los tres colectivos migrantes más relevantes en Tarapacá en los dos últimos censos.

\section{La tendencia al incremento de la población femenina peruana en Tarapacá e Iquique}

Se expresa un marcado predominio de mujeres entre los migrantes peruanos en Tarapacá, según se constata en el censo 2002. Se puede afirmar que se asienta una tendencia a la feminización de la migración peruana, puesto que en la región "las peruanas pasaron de componer 40 por ciento del total de peruanos en la región en 1992, a componer 58.7 por ciento en 2002: un incremento del orden de 18.7 por ciento, muy superior al ritmo de feminización que observamos en la capital Santiago" (Guizardi y Garcés, 2012:22). La Tabla 3 ilustra los números censales para la migración femenina y masculina peruana en Tarapacá entre los censos 1992 y 2002.

Los valores absolutos de la tabla hablan de 148 mujeres peruanas en inicios de los años 1990, y nada menos que 1551 en la década siguiente. Esta tendencia a la feminización debe comprenderse como una equiparación entre las proporciones de hombres y mujeres que migran, considerando que a principios de siglo XX este fenómeno era notoriamente masculino. Por otro lado, la feminización se asocia a factores que exceden el contexto regional tarapaqueño e iquiqueño. i) A las reformas neoliberales vividas por el Perú, las cuales redundaron en un empobrecimiento y precarización del trabajo femenino por encima de la media masculina, posicionando a la migración femenina como una alternativa económica para los procesos de reproducción social de las familias que siguen constituyendo una responsabilidad netamente femenina en el país andino. ii) Se deben también a las dinámicas de internacionalización del trabajo reproductivo (Acosta, 2011; Gonzálvez y Acosta, 2015; Mora, 2008, Setién y Acosta, 2011). ${ }^{25}$

\footnotetext{
${ }^{25}$ La internacionalización del trabajo femenino constituye aquello que algunas autoras enuncian como la formación de "cadenas globales del cuidado" (Acosta, 2011; Gonzálvez y Acosta, 2015; Setién y Acosta, 2011). El fenómeno resulta del hecho de que la inserción femenina al mundo del trabajo no tiene un correlato con el reordenamiento de las tareas reproductivas y de crianza en la familia nuclear, generando cadenas de cuidado internacionales: promoviendo la migración de mujeres que se hacen cargo de dichas tareas. Esta migración, normalmente, más que promover la valoración del papel femenino en los procesos de reproducción social, redundan en formas de explotación, estigmatización y marginación del trabajo de las migrantes. Estas dinámicas se relacionan con las especificidades del mercado laboral de expansión minera en el norte de Chile y su impacto en las relaciones de género.
} 
Configuraciones de la migración femenina peruana en Iquique Chile en el siglo XX! / M. LUBE GUIZARDI et al.

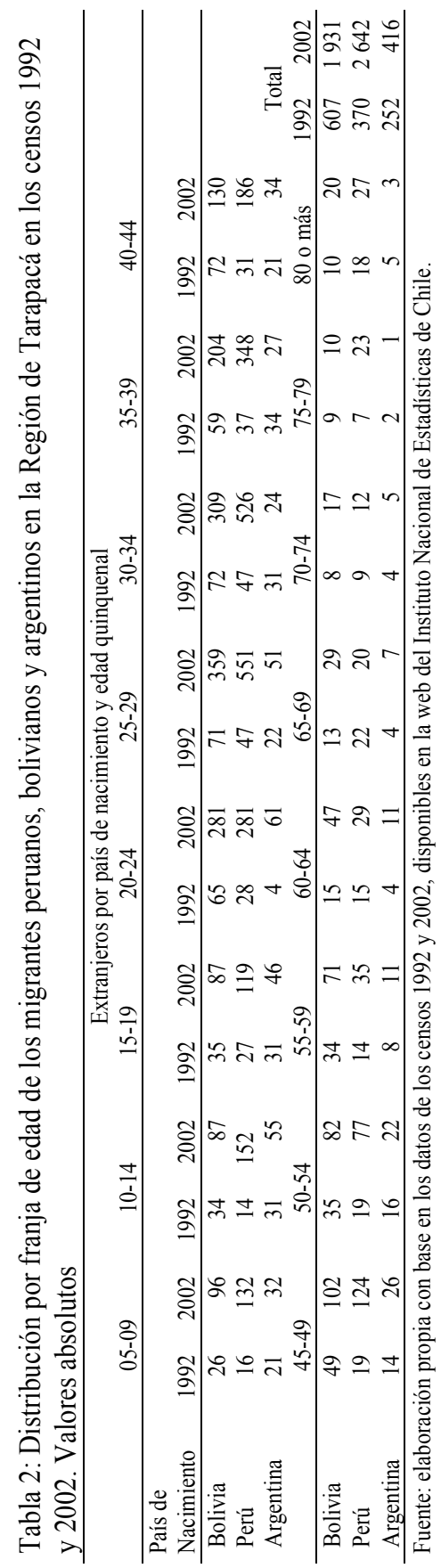


Tabla 3: Migrantes peruanos según sexo en la Región de Tarapacá, censos 1992 y 2002. Valores absolutos

\begin{tabular}{|c|c|c|c|c|c|c|}
\hline \multirow[b]{3}{*}{ Región } & \multicolumn{4}{|c|}{ Sexo del encuestado } & \multirow[b]{3}{*}{ Total } & \multirow[b]{3}{*}{ Total 2002} \\
\hline & \multicolumn{2}{|c|}{ Hombre } & \multicolumn{2}{|c|}{ Mujer } & & \\
\hline & 1992 & 2002 & 1992 & 2002 & & \\
\hline Tarapacá & 222 & 1091 & 148 & 1551 & 370 & 2642 \\
\hline
\end{tabular}

Cuando observamos la caracterización censal de la migración peruana en Tarapacá, nos encontramos con población que posee una media de acceso a la educación formal que es superior a la que presenta la población chilena residente en esta localidad. No obstante, esto no implica que los y las peruanas estarán empleados en nichos laborales correspondientes a su perfil educacional (Guizardi y Garcés, 2012). La Tabla 4 desglosa el periodo de asistencia en años a la educación formal por parte de mujeres y hombres peruanos para cada comuna de Tarapacá. Guizardi y Garcés (2012) han notado en los datos del censo 2002 que las mujeres son proporcionalmente más escolarizadas que los hombres peruanos de la región.

Entre los hombres peruanos, especialmente los que residen en la comuna de Iquique, predominan tiempos de asistencia a la educación formal superior a los 12 años. Entre las mujeres se repite esta misma tendencia. Los migrantes (hombres y mujeres) con más escolaridad formal están concentrados en la comuna de Iquique, lo que nos autoriza a hablar de un perfil calificado de la migración peruana inserta en los espacios urbanos de Tarapacá.

\section{Patrones de auto-adscripción a pueblos indígenas u originarios entre migrantes peruanas}

Con relación a la afiliación a pueblo indígena y originario de los migrantes internacionales en Tarapacá, nos encontramos con tres fenómenos interesantes. i) Para la mayor parte de los sujetos encuestados en los dos censos (1992 y 2002), y para las cuatro nacionalidades más numerosas (peruanos, bolivianos, argentinos y ecuatorianos), predomina la respuesta "ninguna de las etnias mencionadas". 
Configuraciones de la migración femenina peruana en Iquique Chile en el siglo XX! / M. LUBE GUIZARDI et al.

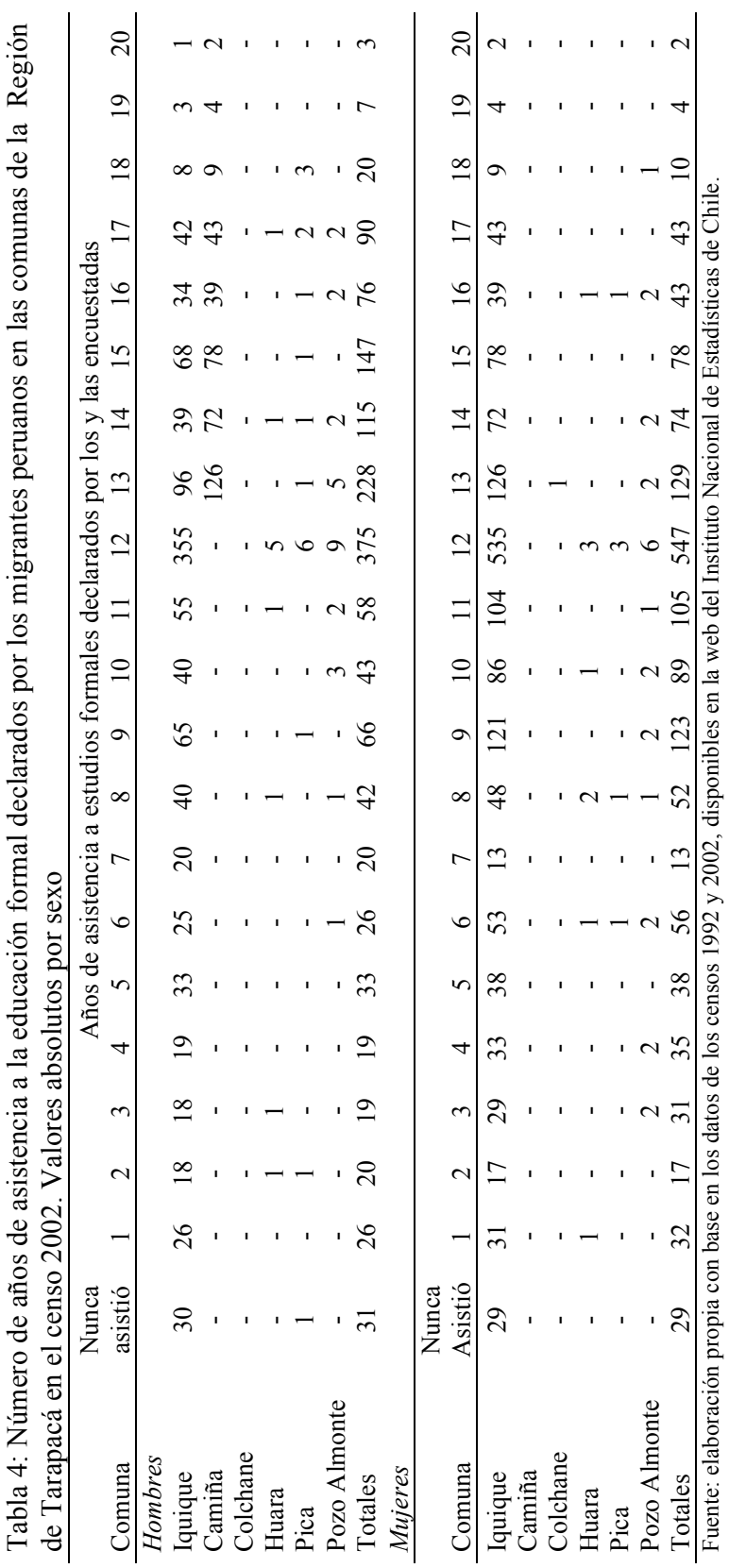


Esto o bien apunta a que los sujetos no se vinculan a ninguna etnicidad (lo que a su vez responde a un sinfín de procesos sociales), o bien a que las opciones de etnicidad mencionadas por la encuesta no satisfacen la auto-adscripción que los sujetos reconocen como suyas. ii) El auto-reconocimiento étnico es más frecuente en los censos 1992 y 2002 entre los migrantes de origen peruano y boliviano, por sobre los otros dos colectivos relevantes (argentino y ecuatoriano) en la región. iii) La etnia con que más frecuentemente se han identificado los y las migrantes peruanas y bolivianas es la aymara (Tabla 5).

$\mathrm{Al}$ centramos en la vinculación a pueblos indígenas $\mathrm{u}$ originarios por parte de los y las peruanas en Tarapacá, en el censo 2002, nos encontramos con una diferencia de género importante. Las mujeres se identifican en más casos con alguna vinculación étnica (8.09 por ciento de ellas lo hace) (Guizardi y Garcés, 2012). El porcentaje es superior al índice de auto-reconocimiento étnico de las mujeres peruanas migrantes en regiones como Antofagasta o Santiago, pero es inferior al índice de 23 por ciento de mujeres peruanas indígenas revelado por el censo 2002 para las actuales comunas de la región de Arica y Parinacota (Guizardi y Garcés, 2012) Tabla 6).

La auto-adscripción étnica es un dato relevante en tanto las dinámicas de producción de la identidad nacional en Chile están asociadas a la diferenciación entre el ideal chileno "criollo-europeo" y la supuesta indigenización de Perú y Bolivia (González, 2008b). La adscripción a una etnia por parte de las migrantes peruanas en Tarapacá las inserta en dinámicas de integración/exclusión, en especial en las dimensiones relacionadas con la economía étnica o la discriminación, estableciendo marcos multidimensionales en su experiencia migrante (Guizardi y Garcés, 2012).

Desglosando el dato del reconocimiento étnico por parte de migrantes peruanos en Tarapacá en 2002, de acuerdo a las comunas o localidades de residencia (Tabla 7), observamos que la mayoría de los migrantes con alguna afiliación étnica se encuentran predominantemente en la comuna de Iquique, en el espacio urbano regional. El dato desafía ciertos lugares comunes que, equivocadamente, podrían proyectar a la población indígena migrante como asentada en espacios de la pampa o del altiplano tarapaqueño. Asimismo, conforme observamos en la Tabla 7, un número relevante de los y las migrantes peruano(a)s, incluyéndose aquellos que no declaran tener vinculación étnica, afirma que residen en otro país, y no en las comunas tarapaqueñas en las que contestaron al cuestionario del censo. 
Configuraciones de la migración femenina percuana en Iquique Chile en el siglo XX! / M. LUBE GUIZARDI et al.

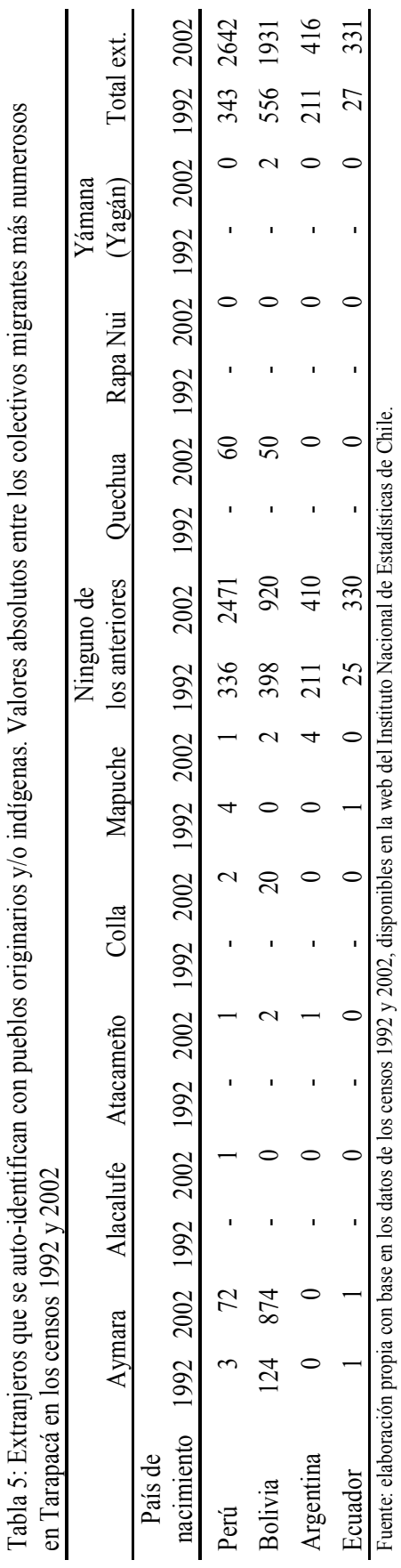


Tabla 6: Migrantes peruanos que declaran pertenecer o vincularse a grupos indígenas y/o originarios en las Regiones chilenas con más concentración de migrantes de esta nacionalidad en el Censo 2002. Valores absolutos por sexo

\begin{tabular}{lrrrr}
\hline Región & Sexo & $\begin{array}{r}\text { Declaran } \\
\text { vínculo étnico }\end{array}$ & $\begin{array}{r}\text { No declaran } \\
\text { vinculación étnica }\end{array}$ & $\begin{array}{r}\text { Total de } \\
\text { personas }\end{array}$ \\
\hline Arica-Parinacota & Hombres & 197 & 727 & 964 \\
Arica-Parinacota & Mujeres & 323 & 934 & 1257 \\
Tarapacá & Hombres & 69 & 1048 & 1117 \\
Tarapacá & Mujeres & 103 & 1170 & 1273 \\
Antofagasta & Hombres & 15 & 410 & 425 \\
Antofagasta & Mujeres & 17 & 526 & 543 \\
Valparaíso & Hombres & 13 & 506 & 519 \\
Valparaíso & Mujeres & 19 & 633 & 652 \\
Santiago & Hombres & 382 & 11401 & 11783 \\
Santiago & Mujeres & 569 & 17876 & 18445 \\
\hline
\end{tabular}

Fuente: elaboración propia con base en los datos de los censos 1992 y 2002, disponibles en la web del Instituto Nacional de Estadísticas de Chile.

El dato constituye un indicio de la condición de intensa movilidad transfronteriza de estos migrantes (Guizardi y Garcés, 2013; Tapia 2013; Tapia y Ovando, 2011; Tapia y Ramos, 2013), desautorizando nociones estatizantes sobre el arraigo migratorio en territorios fronterizos (Tapia y Ovando, 2013; Tapia y Parella, 2015).

\section{Patrones de inserción laboral y redes sociales}

En Chile, las principales áreas productivas en las que se concentran los migrantes peruanos son el comercio, transporte, servicios financieros y servicios comunales sociales (Contreras, Ruiz-Tagle y Sepúlveda, 2013). El discurso mediático chileno promueve la idea de que ciertas prácticas laborales de los migrantes (como aceptar trabajos con baja remuneración y con precarias condiciones laborales) produciría un efecto negativo sobre los salarios de los no migrantes. Los estudios econométricos han desautorizado esta noción. La proporción de migrantes en Chile (2.14 por ciento de la población del país) es tan pequeña que sus "efectos en el mercado laboral son prácticamente nulos" (Contreras, Ruiz-Tagle y Sepúlveda, 2013: 23).

Vergara (2005) señala que las principales actividades económicas de los peruanos en Tarapacá se emplazan en la ciudad, en contraste con los bolivianos que se desplazan hacia el trabajo agrícola. 
Tabla 7: Localidad de residencia de los peruanos que declaran vinculación a un pueblo indígena y/o originario en el censo 2002

\begin{tabular}{|c|c|c|c|c|c|c|}
\hline \multirow[b]{2}{*}{ Comuna } & \multirow{2}{*}{$\begin{array}{l}\text { Pueblos Originarios o } \\
\text { Indígenas con que se } \\
\text { autoidentifican }\end{array}$} & \multicolumn{5}{|c|}{ Donde declaran residir } \\
\hline & & $\begin{array}{r}\text { En esta } \\
\text { comuna }\end{array}$ & $\begin{array}{r}\text { En otra } \\
\text { comuna }\end{array}$ & $\begin{array}{r}\text { En } \\
\text { otro país } \\
\end{array}$ & Ignorado & Total \\
\hline & Alacalufe (Kawashkar) & 0 & 0 & 1 & 0 & 1 \\
\hline & Atacameño & 1 & 0 & 0 & 0 & 1 \\
\hline & Aymara & 25 & 11 & 24 & 0 & 60 \\
\hline & Colla & 2 & 0 & 0 & 0 & 2 \\
\hline & Mapuche & 0 & 0 & 1 & 0 & 1 \\
\hline & Quechua & 51 & 1 & 29 & 2 & 83 \\
\hline & Yámana (Yagán) & 0 & 0 & 1 & 0 & 1 \\
\hline Iquique & Ninguno de los anteriores & 1084 & 74 & 1202 & 36 & 2396 \\
\hline \multirow[t]{3}{*}{ Colchane } & Aymara & 1 & 0 & 0 & 0 & 1 \\
\hline & Aymara & 1 & 2 & 2 & 0 & 5 \\
\hline & Quechua & 4 & 0 & 1 & 0 & 5 \\
\hline \multirow[t]{3}{*}{ Huara } & Ninguno de los anteriores & 4 & 3 & 3 & 0 & 10 \\
\hline & Aymara & 0 & 1 & 1 & 0 & 2 \\
\hline & Quechua & 1 & 0 & 0 & 0 & 1 \\
\hline \multirow[t]{2}{*}{ Pica } & Ninguno de los anteriores & 4 & 12 & 5 & 0 & 21 \\
\hline & Aymara & 1 & 0 & 3 & 0 & 4 \\
\hline Pozo & Quechua & 1 & 2 & 1 & 0 & 4 \\
\hline Almonte & Ninguno de los anteriores & 9 & 16 & 18 & 1 & 44 \\
\hline
\end{tabular}

Fuente: elaboración propia con base en los datos de los censos 1992 y 2002, disponibles en la web del Instituto Nacional de Estadísticas de Chile.

En el caso de las mujeres, la autora identifica que éstas se emplean principalmente como trabajadoras de casa particular en el área de aseo. La inserción laboral en el caso de las mujeres estará enfocada en la economía informal, el servicio doméstico y el pequeño comercio (Guizardi y Garcés, 2012; Vergara, 2005; Tapia 2012).

Sobre las condiciones de trabajo de los migrantes en Tarapacá, dos elementos son característicos (Tabla 8). Por un lado, el desempleo es indicado como menor entre los migrantes que entre los chilenos (Vergara, 2005). Esto porque los migrantes se integran a actividades del mercado laboral despreciadas por los chilenos: nichos con bajas remuneraciones o condiciones precarias que permanecen disponibles (Rojas y Bueno, 2014). 
Tabla 8: Situación de laboral los migrantes peruanos en la Región de Tarapacá en el Censo 2002. Valores absolutos por sexo

\begin{tabular}{|c|c|c|c|c|c|}
\hline Sexo & $\begin{array}{l}\text { Trabajando } \\
\text { por ingreso }\end{array}$ & $\begin{array}{r}\text { Sin trabajar, } \\
\text { pero tiene } \\
\text { empleo } \\
\end{array}$ & $\begin{array}{r}\text { Buscando } \\
\text { trabajo, } \\
\text { habiendo } \\
\text { trabajado antes } \\
\end{array}$ & $\begin{array}{r}\text { Trabajando para } \\
\text { un familiar sin } \\
\text { pago en dinero }\end{array}$ & $\begin{array}{r}\text { Buscando } \\
\text { trabajo por } \\
\text { primera vez }\end{array}$ \\
\hline Hombres & 682 & 23 & 83 & 3 & 7 \\
\hline Mujeres & 801 & 18 & 51 & 3 & 6 \\
\hline & $\begin{array}{r}\text { En } \\
\text { quehaceres } \\
\text { de su hogar }\end{array}$ & Estudiando & $\begin{array}{r}\text { Jubilado o } \\
\text { Rentista } \\
\end{array}$ & $\begin{array}{r}\text { Incapacitado } \\
\text { permanente para } \\
\text { trabajar }\end{array}$ & $\begin{array}{r}\text { Otra } \\
\text { situación }\end{array}$ \\
\hline Hombres & 9 & 53 & 30 & 3 & 57 \\
\hline Mujeres & 400 & 50 & 21 & 4 & 54 \\
\hline
\end{tabular}

La búsqueda de empleo y la permanencia en Chile se relaciona con las complicaciones documentales que se imponen a los migrantes sin contrato laboral (Stefoni, 2011; Jensen, 2009). El segundo elemento indicado como característica de la condición laboral de estos migrantes es la precariedad: los bajos salarios en comparación a los trabajadores chilenos (Vergara, 2005). La situación de precarización migrante se identifica porque en muchos casos la necesidad imperiosa de mantener a una familia en el lugar de origen obliga a aceptar este tipo de empleos con bajos sueldos (Berganza y Cerna, 2011:138).

Las formas del trabajo permiten identificar dinámicas sociales y culturales de migración que distinguen a un número significativo de migrantes peruanos. Así, colectivos que se desenvuelven como temporeros agricultores y comerciantes y que poseen antecedentes aymara suelen responder a dinámicas migratorias particulares (Garcés y Moraga, 2015). En estos casos, son trabajadores que poseen familia tanto en Chile como Perú y Bolivia y que generan circuitos laborales entre estos tres países basados en economías de producción familiar (Guizardi y Garcés, 2013).

El proceso de inserción de los migrantes en Iquique está dado por una multiplicidad de factores entre los que destacan principalmente las redes sociales transnacionales ${ }^{26}$ en origen y destino. Así, por ejemplo, Tapia y

${ }^{26}$ El concepto de red social transnacional que adoptamos aquí reincorpora la definición de Guizardi y Garcés (2013), quienes caracterizan a estas redes como formas y prácticas de conexión social de los grupos y comunidades que establecen vínculos constantes, aun cuando son cambiantes, entre, más allá y a pesar de las fronteras nacionales y de sus restricciones. 
Ramos (2013) han estudiado la acción de los servicios religiosos como la Pastoral de Migraciones como institución de acogida y apoyo en la inserción laboral de las mujeres peruanas y bolivianas en Iquique. Las redes formadas entre individuos e instituciones constituyen un canal de acceso a recursos en términos materiales, laborales o de información. Pero también influyen en la estructuración, crecimiento y composición de la comunidad en Chile (Tapia y Ramos, 2013: 248). Asimismo, las condiciones de cercanía que posee Tarapacá con respecto a Perú les permiten a las mujeres migrantes peruanas cierta flexibilidad en la generación de estrategias para la reproducción social de sus familias y de su propia experiencia migrante mediante la circularidad de su migración. El retorno al país de origen se mantiene como una opción plausible dependiendo del grado de éxito del proyecto migratorio. Esta flexibilidad está apoyada por la condición más accesible a los trabajos por parte de los migrantes, ya sea por el carácter de estos (precarios) ya sea por las redes transnacionales (Tapia y Ramos, 2013). En Tarapacá, las redes migrantes permiten la articulación entre las mujeres migrantes y un mercado laboral concreto: cuidados y servicios domésticos (Tapia y Ramos, 2013: 248).

Pero la construcción de estas redes ha sido un proceso paulatino. Los peruanos que llegaron a Tarapacá en la década de 1990 no poseían este recurso, por lo que tuvieron que enfrentar difíciles situaciones de mayor precariedad en comparación a quienes migraron posteriormente. ${ }^{27}$ Con la llegada de la segunda oleada, ya se encontraron con una primera red de apoyo creada por "los campistas". Como señalan Berganza y Cerna (2011: 139), "quienes llegaron con las siguientes oleadas, encontraron una estructura que les permitió acceder a trabajo y lugares de residencia. La decisión de emigrar, entonces, no solo pasó por un tema de evaluación de aspectos socioeconómicos del país de origen ni de Chile, sino de redes sociales". Estas estructuras fueron posibles ya que, según estos autores, la población migrante que llegó durante los primeros años del siglo XXI procedía de localidades comunes. ${ }^{28}$ Las redes comunitarias en origen actuaron como elemento de construcción de la movilidad e inserción en Iquique.

Las redes, en especial las conformadas por familiares, son parte fundamental de la experiencia migratoria. Por un lado, en muchas ocasiones, la migración se realiza para el mejoramiento de la calidad de vida de la

${ }^{27} \mathrm{La}$ ausencia de redes que permitieran sustentar en un primer instante la estancia en Chile llevó a muchos a incluso tener que pernoctar en carpas, situación que les valió el nombre de "campistas" (Berganza y Cerna, 2011: 139)

${ }^{28}$ Estas redes migrantes eran localizables en determinados sectores específicos en el país de origen: en el norte chico peruano (Huacho, Barranca, Supe), en la zona norte (Chimbote y Trujillo) y zona sur (Tacna y Puno) (Berganza y Cerna, 2011). 
familia en origen, por lo que el mantenimiento de las redes entre origen y destino no sólo es práctico, sino que es una de las causas de la migración. Por otro lado, como indican Berganza y Cerna (2011), las redes permiten obtener recursos y compartir información con destino, transmitiendo una impronta migratoria e impulsando a nuevos migrantes. En el caso de Iquique, así como en las demás localidades del Norte Grande, quien ha cumplido el rol de ser cabecilla de las migraciones peruanas y establecer los primeros lazos entre origen y destino son las mujeres (Guizardi y Garcés, 2012; Guizardi y Garcés, 2013; Guizardi y Garcés, 2014a). ${ }^{29}$

Pero las ventajas de las redes no radican solo en el mayor acceso a recursos, trabajos e información, sino que también a espacios de recreación o mecanismos de identificación y soporte espiritual, como es el caso de las fiestas y servicios religiosos. Así, por ejemplo, la hermandad del Señor de los Milagros de Iquique "permite recrear una imagen de comunidad unida y homogénea, de los inmigrantes peruanos" (Berganza y Cerna, 2011: 160), disputando la concepción del migrante peruano frente a la representación negativa hegemónica que recae sobre los migrantes.

\section{Consideraciones finales. Aportes para comprender}

\section{LOS PROCESOS DE ALTERIDAD MIGRANTE}

La región de Tarapacá comparte con las demás regiones del Norte Grande (Arica y Parinacota y Antofagasta), y también con los territorios colindantes sur-peruanos, del noroeste argentino y del suroeste de Bolivia, una particular condición de heterogeneidad social y cultural. Sin embargo, la sedimentación de las experiencias sociales que configuraban la relación entre permanencia y movilidad, para los distintos grupos que vivieron sobre estos territorios en los últimos seis siglos, sufrió un quiebre tras el fin de la Guerra del Pacífico. Esto se observa muy claramente durante las últimas décadas del siglo XIX y las primeras décadas del siglo XX, en el proceso conocido como chilenización. Éste significó la ejecución de un proyecto estatal, nacional e identitario mediante mecanismos de violencia

\footnotetext{
${ }^{29}$ La llegada de jefas de hogar al país de destino abre una nueva problemática: la maternidad transnacional (Acosta, 2011; Godoy, 2007; Guizardi y Garcés, 2012; Setién y Acosta, 2011; Stefoni, 2009; Stefoni y Fernández, 2011). Si bien el avance en las comunicaciones ha aportado al acortamiento de las distancias, la crianza transnacional de los hijos es siempre un desafío. Las estrategias son variadas y pueden ir desde estancias cortas en el territorio chileno para luego retornar, una maternidad transnacional basada en la comunicación telefónica y virtual con visitas esporádicas o, la reagrupación familiar en destino. En el caso de la reagrupación, la crianza presenta algunos desafíos, como por ejemplo el desarraigo del territorio de origen, el acceso a educación de calidad, movilización de redes para el cuidado de los hijos.
} 
simbólica y física llevados a cabo por parte del Estado chileno, grupos civiles y paramilitares.

Las acciones buscaban que peruanos, bolivianos e indígenas en general "asimilaran" aquello que en este momento se definía como la "chilenidad"; constituyéndose así un proceso identitario, étnico y nacional que impactó fuertemente en las diferenciaciones de los tres países. Así, la construcción de la identidad nacional chilena, en el caso tarapaqueño, es un fenómeno reciente, pero no por ello menos vigoroso. En efecto, al constituirse como un proceso de construcción de las fronteras (González, 2008b), el proyecto de identidad nacional en Tarapacá se ejerce con gran fuerza, potenciando la constante reactualización de los límites entre grupos y espacios (Vergara y Gundermann, 2007). El territorio se encuentra, hasta la actualidad, marcado por las contradicciones del choque entre los grupos sociales heterogéneos y estas ideas de nación producidas por la administración central chilena.

Además de esta contradicción, inciden distintos factores sociales en el territorio que particularizan esta heterogeneidad fronteriza. Se cruzan bajo la identidad tarapaqueña múltiples formas de identidades (Vergara y Gundermann, 2007). Éstas se relacionan a la multiplicación de procesos sociales y modos de vida, cuyas variaciones se hacen notar de localidad a localidad; de provincia a provincia, de barrio a barrio. En estas diversificaciones de los principios, modos y formas de construcción de la identidad en Tarapacá, incidirán - además, de las asignaciones de nacionalidad (chilena, peruana, boliviana) y de las etnias - la experiencia social de vivir y pertenecer a espacios urbanos, rurales, altiplánicos o pampinos.

En el caso de las identidades definidas por determinadas unidades geográficas y políticas, Vergara y Gundermann (2007) reconocen un especial arraigo en espacios locales (como en el caso de Pica) o barriales (como en el caso de Iquique). De la misma forma, se identifican niveles emergentes y más complejos de identidad que reconocen a la provincia como espacio mayor de arraigo. En este caso, cabe destacar que el "ser iquiqueño" no sólo se constituye de manera sustancial, sino que también a partir de la distención interregional, como quedó claro en las disputas históricas entre la provincia de Iquique y la de Arica (Vergara y Gundermann, 2007). Pero así mismo, la identidad "iquiqueña" también sirve para constituir diferencias en el espacio provincial y comunal, con el objeto de diferenciar a los "nativos" de los "afuerinos". A estos últimos, se les atribuye la emergencia 
o profundización de los problemas de la ciudad y se les culpa de su degradación (Vergara y Gundermann, 2007). ${ }^{30}$

Volviendo a la cuestión de la auto-identificación étnica, que discutímos en apartados anteriores, existe en Tarapacá una población aymara de alrededor de 40.000 personas. Como indica González (2000, en Vergara y Gundermann, 2007), las identidades locales predominan por sobre la identidad genérica "aymara". No obstante, la auto-adscripción a este pueblo es más bien un proceso reciente debido al mismo proceso de chilenización. ${ }^{31}$ En esto inciden las también recientes políticas estatales de reconocimiento étnico en Chile que se vienen implementando solo a partir de 1996 (Gundermann, 2013). Como consecuencia de las prácticas de chilenización y resignificación étnica, los aymara en Tarapacá actualmente ejercen una doble identidad que reivindica, simultáneamente, el ser indígena y el ser chileno. (González, 2000 en Vergara y Gundermann, 2007).

En términos de prácticas, el espacio social tarapaqueño se constituye como un reflejo de las contradicciones de estas distintas identidades. Por un lado, como indican Mondaca, Rivera y Gajardo (2014: 254-256), las prácticas de chilenización que aún se reflejan en ritos y actos públicos tienen su mayor expresión en la permanente intención del Estado, y la administración central, por la educación nacionalista impartida, en particular, en las escuelas públicas. Por otro lado, en la región se encuentran distintas expresiones que dan cuenta de la complejidad cultural, tensionando la constitución de soberanías a través de procesos pretendidamente delimitadores de las diferencias entre las identidades chilena, peruana y boliviana. Este es el caso claro de las fiestas religiosas como la Tirana, en la cual se enfrentan y combinan distintos elementos indígenas, cristianos, chilenos, peruanos y bolivianos. La complejidad del ritual refleja esta situación mediante el sincretismo religioso que logra articular, a partir de un credo en particular, las prácticas cristianas, indígenas y populares (Guerrero, 2011), siendo un espacio de producción y reproducción de la heterogeneidad cultural de la zona.

${ }^{30}$ Quizás el elemento de identificación macro-regional superior a las identidades locales y que posee un fuerte arraigo sea el de "pampino", constituido principalmente durante el periodo de la Gran Minería. Actualmente se pueden encontrar distintas asociaciones que responden a esta identidad. Una particularidad de esta identificación es que permite aunar distintos sectores sociales (regionales, nacionales e internacionales) a partir del reconocimiento de un pasado asociado a esta productividad (Vergara y Gundermann, 2007).

${ }^{31}$ Tanto el proceso de chilenización como el de reconstitución de lo "aymara" encuentran parte de su fundamento en políticas estatales de aculturación o resignificación indígena. Asimismo, también son objeto de una apropiación simbólica, económica y política por parte de los grupos sociales aymara, lo que implica que estos procesos ocupen, dialécticamente, un lugar de reproducción de violencias identitarias históricas, y un lugar de resistencia y resignificación social de éstas. 
Pero lo que nos interesa particularmente con relación a la complejidad de la cuestión identitaria y étnica en Tarapacá es la comprensión de cómo esto impacta la realidad migrante en estos territorios; y específicamente en la ciudad de Iquique. A propósito, queremos ahora apuntar una premisa inductiva que surge a partir de nuestro proceso reflexivo. $\mathrm{Si}$, como expusimos páginas atrás, la chilenización se constituyó a partir de imaginar que peruanos y bolivianos son "indígenas"; entonces la violencia de la chilenización siembra en Tarapacá (a través de la escuela, de los aparatos militares y de los aparatos culturales) la ideología de que peruanos y bolivianos son degenerados porque, precisamente, son indígenas. Es decir, la chilenización operacionalizó una forma particular (y violenta) de etnificación del otro peruano y boliviano; y generó una nacionalización de esta identidad etnificada (que a menudo se expresa en frases condensadoras del tipo: "todos los peruanos son cholos indígenas").

Pero esta violencia chilenizadora también se experimentó desde los propios aymara que quedaron en territorio tarapaqueño: también ellos sufrieron las violencias de la chilenización. Dado que son etnificados, dado que son indígenas, son chilenos que acceden a una condición nacional inconclusa o insuficiente desde la perspectiva normativa del paradigma étnico chileno, el cual se enuncia desde el centro del país, proyectando mitologías de auto-representación de ciertas élites políticas (Grimson y Guizardi, 2015; Guizardi et al., 2015). Los indígenas del norte chileno acceden, así, a una especie de chilenidad de segunda categoría (Stefoni, 2005).

En el contexto actual, en el que se vive un proceso global que impele a la re-etnificación de los grupos y, sobre todo, de sus territorios y bienes materiales (Comaroff y Comaroff, 2009), los indígenas descubrieron que su etnicidad es producto global, exótico y valorado. También lo ha descubierto el Estado chileno, el cual viene invirtiendo recursos en potenciar la etnificación del turismo internacional en el Desierto de Atacama. En Tarapacá, un lugar donde la chilenidad nacionalizante operó de forma tan fragmentada, tan asimétrica y desigual, esta nueva valoración global de lo étnico reafirma la contradicción entre términos identitarios (chilenos como criollos-europeos, versus peruanos y bolivianos como indígenas) que la chilenización de estos espacios construyó. Así, se podría incluso llegar a postular que la intensificación migratoria de aymara peruanos y bolivianos a Tarapacá termina por asimilarse según una jerarquía mitológica de lo étnico: reproduciendo la diferencia entre chilenos y migrantes peruanos y bolivianos en general; y estableciendo además una diferenciación jerárquica entre aymara chilenos y los de las naciones colindantes. Y esto deriva 
del cruce de las ideologías de chilenización, con las actuales ideologías de re-etnificación.

Estas complejas interacciones entre identidades inciden en la forma como se representa a los migrantes peruanos y se materializan en una discriminación que se siente mucho más fuerte en el caso de las mujeres de esta nacionalidad (Guizardi y Garcés, 2012). Cabe aquí, desde los datos contextuales que desarrollamos en este artículo, establecer conexiones acerca de la constitución identitaria y étnica de la experiencia social en los territorios de Tarapacá e Iquique. Hablamos de un contexto económico de expansión de la economía minera que demanda la migración de trabajadores chilenos y extranjeros a la zona. Pero también hablamos de un modelo de configuración económica que no solamente aumenta la brecha entre clases sociales (con tendencias consolidadas a la concentración de renta), sino que lo hace a través de aumentar las distorsiones de género (dada la concentración de mejores posibilidades de rentas entre trabajadores hombres).

Por otro lado, hablamos que la presencia necesaria de trabajadores peruanos en las faenas de minas se sigue asumiendo localmente a través de imaginarios y representaciones que reproducen las distancias identitarias entre chilenos y peruanos. Estas dos tendencias se hacen acompañar, como hemos mostrado, por una tercera: la feminización de la migración peruana en estos territorios. Estos datos nos permiten proyectar que la experiencia femenina migrante peruana, en este complejo cruce entre formas estructurales económicas, procesos históricos de la alteridad nacional y distorsiones de género, termina por reproducir el tradicional cruce entre los tres elementos más centrales en la formación de las desigualdades sociales en el capitalismo actual, tal como lo definieron Wallerstein y Balibar (1991: 49): los universalismos (nacionalistas en este caso), el racismo y el sexismo.

\section{REFERENCIAS BIBLIOGRÁFICAS}

Acosta, E., 2011, "Valorar los cuidados al estudiar las migraciones: la crisis del trabajo de cuidado y la feminización de la inmigración en Chile", en Stefoni, C. (Ed.) Mujeres inmigrantes en Chile ¿Mano de obra o trabajadoras con derecho?, pp. 193-228. Editorial de la Universidad Alberto Hurtado. Santiago de Chile.

Adán, L., Urbina, S., y Uribe, M., 2007, “Arquitectura pública y doméstica en las quebradas de Pica-Tarapacá: Asentamiento y dinámica social en el Norte Grande de Chile (900-1450 DC)", en Nielsen, A., Rivolta, M.C., Vázquez, M. y Mercollí, P. (Comps). Procesos sociales prehispánicos en el sur andino: La vivienda, la comunidad, y el territorio, pp.183-206. Editorial Brujas. Córdoba.

Araújo, K., Legua, M.C. y Ossandón, L., 2002, Migrantes andinas en Chile. El caso de la migración peruana. Fundación Instituto de la Mujer. Santiago de Chile. 
Bähr, J., 1980, "Migraciones en el Norte Grande de Chile. Resultados de un análisis de movimientos migratorios entre los años 1965 y 1970", en Revista de Geografia Norte Grande, (7):3-20.

Berganza, I. y Cerna, M., 2011, Dinámicas migratorias en la frontera Perú-Chile. Arica, Tacna e Iquique. Fondo Editorial. Lima.

Carrasco, C. y Vega, P., 2011, Una aproximación a las condiciones de trabajo en la Gran Minería de Altura. Dirección de Trabajo del Gobierno de Chile. Santiago de Chile.

Castles, S. y Miller, M., 2004, La era de la migración. Movimientos internacionales de población en el mundo moderno. UAZ/INM/Fundación Colosio. México.

CIPTAR, 2012, Desarrollo económico y productivo de Tarapacá. Línea de base económica de la región de Tarapacá. CIPTAR. Iquique.

Comaroff, J., 1985, Body of Power, Spirit of Resistance. The Culture and History of a South African People. University of Chicago Press. Chicago.

Comaroff, J.L. y Comaroff, J., 2009, Etnicidad SA. Katz. Buenos Aires.

Compañía Minera Doña Inés de Collahuasi, 2008, Desarrollo Humano y Socioeconómico de la Región de Tarapacá 1990-2007. EC SOURCE. Iquique.

Congreso Nacional de Chile, 2007, Historia de la Ley 20.175: Crea la XV Región de Arica y Parinacota y la provincia del Tamarugal en la Región de Tarapacá. Santiago: Biblioteca del Congreso Nacional de Chile. Disponible en http://www. bcn.cl/histley/lfs/hdl-20175/HL20175.pdf (Consultado 12/04/2014).

Contreras, D. Ruiz-Tagle, J y Sepúlveda, P., 2013, Migración y mercado laboral en Chile. Univesidad de Chile. Santiago de Chile.

Departamento de Extranjería y Migración del Ministerio del Interior de Chile (DEM), 2010, Informe anual de Extranjería y Migración. Ministerio del Interior de Chile. Santiago de Chile.

Dittmar, M., 1996, “Los Aymara prehispánicos y actuales: etnogénesis, microdiferenciación y su relación con la población Tiwanaku de América del Sur", en Revista Española de Antropología Americana, 26, 231.

Erazo Vega, C., 2009, "Situación social de los inmigrantes latinoamericanos en la ciudad de Antofagasta, Chile", en Hombre y Desierto. Una perspectiva Cultural, 15: 139-162.

Gana, A., 2014, "Etnografía de los comercios inmigrantes en los barrios del estudio de casos", en Arriagada, C.L. (ed.). Inmigrantes internacionales. Emprendimientos en barrios comerciales Iquique, Gran Valparaíso y Santiago de Chile, pp. 70-92. FAU. Santiago de Chile.

Garcés, A. y Moraga, J., 2015, "Reconfiguraciones de la economía y sociedad aymara en la frontera de Chile y Bolivia: el caso Colchane-Pisiga", en Cardín, E., Arriaga, J.C. y Camal-Cheluja, T. (eds.), Fronteras y dinámicas trasfronterizas en América Latina. Chetumal: Universidad de Quintana Roo. 
Godoy, L., 2007, "Fenómenos migratorios y Género: identidades 'remodeladas", en Psykhe, 16(1): 41-51.

González Miranda, S., 1994, "El poder del símbolo en la chilenización de Tarapacá. Violencia y Nacionalismo entre 1907-1950", en Revista de Ciencias Sociales Universidad Arturo Prat, (5), p. 42-56.

González Miranda, S., 2002a, Hombres y mujeres de la Pampa: Tarapacá en el ciclo de expansicón del salitre. LOM. Santiago de Chile.

González Miranda, S., 2002b, Chilenizando a Tunupa. La escuela pública en el Tarapacá andino 1800-1990. DIBAM. Santiago de Chile.

González Miranda, S., 2004, El Dios cautivo: las Ligas Patrióticas en la chilenización compulsiva de Tarapacá, 1910-1922. Ediciones Lom. Santiago de Chile.

González Miranda, S., 2007, Ofrenda a una masacre. Claves e indicios históricos de la emancipación pampina d 1907. LOM. Santiago de Chile.

González Miranda, S., 2008a, La llave y el candado. El conflicto entre Perú y Chile por Tacna y Arica. LOM Ediciones. Santiago de Chile.

González Miranda, S., 2008b, "El norte grande de Chile: la definición histórica de sus límites, zonas y líneas de frontera, y la importancia de las ciudades como geosímbolos fronterizos", en Revista Idea, 2(13), s/n.

González Miranda, S., 2009, "La presencia boliviana en la sociedad del salitre y la nueva definición de la frontera: auge y caída de una dinámica trasfronteriza, Tarapacá 1880-1930", en Revista Chungará, 41(1): 71-81.

González Pizarro, J.A., 2008, "La emigración boliviana en la precordillera de la región de Antofagasta, 1910-1930. Redes sociales y estudios de caso", en Revista de Ciencias Sociales de la Universidad Arturo Prat, 21, 61-85.

Gonzálvez, H. y Acosta, E., 2015, "Cruzar las fronteras desde los cuidados: la migración transnacional más allá de las dicotomías analíticas”, en Guizardi, M. (ed). Las fronteras del Transnacionalismo. Limites y desbordes de la experiencia migrante en el centro y norte de Chile. Ocho Libros. Santiago de Chile.

Grimson, A. y Guizardi, M.L., 2015, "Matices y límites del trasnacionalismo: los contextos de la migración en Chile", en Guizardi, M. (ed). Las fronteras del Transnacionalismo. Límites y desbordes de la experiencia migrante en el centro y norte de Chile. Ocho Libros. Santiago de Chile.

Grimson, A., 2011, Los límites de la cultura. Crítica de las teorías de la identidad. Siglo Veintiuno Editores. Buenos Aires.

Guerrero, B., 2007, Nunca la flor creció. Centenario de la Matanza de la Escuela de Santa María. Ediciones Campvs de la Universidad Arturo Prat de Iquique y El Jote Errante. Iquique.

Guerrero, B., 2011, "Historia, identidad y estéticas andinas y populares en los estandartes de los bailes religiosos en la fiesta de la Tirana", en Revista de Humanidades, (24), 161-175. 
Guerrero, V., 2014, "El nuevo espacio social de Tarapacá: las claves de una nueva sociabilidad", en Diálogo andino, (45), 215-224.

Guizardi, M.L. y Garcés H., A., 2012, “Mujeres Peruanas en las Regiones del Norte de Chile: Apuntes Preliminares para la Investigación”, en Estudios Atacameños, 44: 5-34.

Guizardi, M.L. y Garcés H., A., 2013, “Circuitos migrantes. Itinerarios y formación de redes migratorias entre Perú, Bolivia, Chile y Argentina en el norte grande chileno", en Papeles de Población, 19(78), 65-110.

Guizardi, M.L. y Garcés H., A., 2014a, “Estudios de caso de la migración peruana 'en Chile': un análisis crítico de las distorsiones de representación y representatividad en los recortes espaciales", en Revista de Geografía Norte Grande, 58, 223-240.

Guizardi, M.L. y Garcés H., A., 2014b, "Historizar el espacio: reflexiones sobre la construcción del recorte espacial en un estudio sobre las migraciones peruanas y bolivianas en el Norte Grande de Chile", en Revista Ágora, (19), 27-56.

Guizardi, M.L., Heredia, O., Muñoz, A., Dávila, G. y Valdebenito, F. 2014, “Experiencia migrante y apropiaciones espaciales: un etnografía visual en las inmediaciones del Terminal Internacional de Arica, Chile", en Revista de Estudios Sociales, 48: 166-175.

Guizardi, M.L., Valdebenito, F., López, E. y Nazal, E., 2015, “Condensaciones en el espacio hiperfronterizo: Apropiaciones migrantes en la frontera Norte de Chile", en Guizardi, M. (ed). Las fronteras del Transnacionalismo. Límites y desbordes de la experiencia migrante en el centro y norte de Chile. Ocho Libros. Santiago de Chile.

Gundermann, H., 2013, "Procesos étnicos y cultura en los pueblos indígenas de Chile", en Alpha (Osorno), (36), 93-108.

Gundermann, H., y González Cortéz, H., 2008, "Pautas de integración regional, migración, movilidad y redes sociales en los pueblos indígenas de Chile", en Universum (Talca), 23(1):82-115

Gundermann, H., y Vergara, J.I., 2009, “Comunidad, organización y complejidad social andinas en el norte de Chile", en Estudios Atacameños, (38):107-126.

Gundermann, K., y Foerster, G., 2005, “Contar a los indígenas en Chile: Autoadscripción étnica en la experiencia censal de 1992 y 2002”, en Estudios atacameños, (30), 91-113.

Hidalgo Vallejos, A., 2004, Etnogénesis Aymara: Los procesos de reetnificación y los cambios en las expectativas sobre educación y movilidad social en las comunidades aymaras de Arica y Parinacota (Chile) 1980-2000. Memoria para optar al grado de Magíster en Historia. Mención Historia de América. Universidad de Chile. Santiago de Chile, Chile.

INE, 2009, Anuario Regional Tarapacá 2008. Instituto Nacional de Estadística de Chile, INE, Iquique. 
INE, 2010, Metodología Indicador de actividad económica regional (INACER) año base 2003. INE. Santiago de Chile.

INE, 2014a, Indicador De Actividad Económica Regional. BoletínInformativo Del Instituto Nacional De Estadisticas. INE. Santiago de Chile.

INE, 2014b, "Reporte Comunal: Iquique, Región de Tarapacá". Serie Informes Comunales. INE. Santiago de Chile.

INE, 2015, Informe de Empleo Regional, Región de Tarapacá. Boletín Informativo del Instituto Nacional de Estadísticas. INE. Tarapacá.

Jensen, M.F., 2009, "Inmigrantes en Chile: la exclusión vista desde la política migratoria chilena", en Bolgna, E. (Org.), Temáticas migratorias actuales en América Latina: remesas, politicas y emigración, pp. 105-130. ALAP. Río de Janeiro.

Jensen, M.F., 2014, “'Donde fueras, haz lo que vieras': integración de migrantes en el Chile contemporáneo", en Imilan, W., Garcés, A y MArgarit, D. (Eds.). Poblaciones en Movimiento. Etnificación de la ciudad, redes e integración, pp. 99-120. Ediciones Universidad Alberto Hurtado. Santiago de Chile:

Katzman K., R., 2014, "Iquique ciudad joven de frontera. Estrategias y experiencias de los inmigrantes internacionales en Iquique para superar su vulnerabilidad a la exclusión social", en Arriagada, C.L. (ed.) Inmigrantes internacionales. Emprendimientos en barrios comerciales Iquique, Gran Valparaíso y Santiago de Chile, pp. 117-141. Santiago de Chile: FAU.

Lipszyc, C., 2004, Feminización de las Migraciones: Sueños y Realidades de las Mujeres migrantes en cuatro países de América Latina. Ponencia presentada en el Encuentro Caminar sin Miedos, 13-15 abril, en Montevideo Uruguay.

Martínez Pizarro, J., 2003, "Breve examen de la inmigración en Chile según los datos generales del Censo de 2002", en Documentos para Trabajo OIM, 3: 1-20.

Martínez Pizarro, J., 2005, Magnitud y dinámica de la inmigración en Chile, según censo 2002", en Papeles de Población, 44: 109-147.

Mauss, M., 1979, "Ensayo sobre los dones, Motivo y forma de los cambios en las sociedades primitivas, en Mauss, M., Sociología y Antropología, pp.155-195. Editorial Tecnos. Madrid.

Ministerio de Desarrollo Social, 2013, Resultados Regionales Encuesta Casen 2011: Región de Tarapacá, Serie Informes Regionales, núm. 1. Ministerio de Desarrollo Social. Tarapacá.

Ministerio de Desarrollo Social, 2015, “¿Qué es un complejo Fronterizo?”, Disponible en http://www.pasosfronterizos.gov.cl/que_es_un_complejo.html (Consultado en 01/05/2015).

Mondaca, C., Rivera, P., y Gajardo, Y., 2014, "Educación parvularia e inclusión en el Norte de Chile: formando pequeños chilenos en las aulas de Tarapacá", en Alpha (Osorno), (39), 251-266.

Mora, C., 2008, “Globalización, género y migraciones”, en Revista Polis, 7(20): 285-297. 
Navarrete Yáñez, B., 2007, “La quinta oleada migratoria de peruanos a Chile: los residentes legales”, en Revista Enfoques, 7: 173-195.

Nielsen, A.E., 1997, "El tráfico caravanero visto desde la Jara”, en Estudios Atacameños, (14): 339-371.

Núñez, L. y Nielsen, A., 2011, “Caminante, sí hay camino: Reflexiones sobre el tráfico sur andino”, en Núñez, L. y Nielsen, A., (eds.), Ruta. Arqueología, Historia y Etnografía del tráfico sur andino, pp. 11-41. Encuentro. Antofagasta.

Núñez, L. y T.S. Dillehay, 1979, Movilidad Giratoria, Armonía Social y Desarrollo en los Andes Meridionales: Patrones de Tráfico e Interacción Económica. Universidad Católica del Norte. Antofagasta:

Núñez, Lorena y Holper, D., 2005, “En el Perú, nadie se muere de hambre’: pérdida de peso y prácticas de alimentación entre trabajadoras domésticas peruanas", en El quinto suyo. Transnacionalidad y formación diaspórica en la migración peruana, (eds.) Ulla D. Berg y Karsten Paerregaard, 291-313. Instituto de Estudios Peruanos. Lima.

Núñez, N. y Torres, C., 2007, Mujeres migrantes peruanas y salud reproductiva. Usuarias de consultorios de salud de la Zona Norte de la Región Metropolitana. Fundación Instituto de la Mujer. Santiago de Chile.

OIM, 2013a, Taller de Certificación de Competencias Profesionales y Migraciones. OIM: Ciudad de Guatemala.

Poblete Melis, R., 2006, Educación intercultural: teorías, políticas y prácticas. La migración peruana en el Chile de hoy. Nuevos escenarios y desafios para la integración. Disertación doctoral defendida en la Universidad Autónoma de Barcelona, en Cataluña, España.

Rojas, N. y Bueno, S., 2014, "Redes de inclusión. Estudios sociolaborales de migrantes en Arica”, en Rojas, N y Vicuña, J.T, Migración y Trabajo. Estudio y propuestas para la inclusión sociolaboral de migrantes en Arica, pp. 56-100. OIMCiudadano Global. Santiago de Chile.

Sanhueza, C., 2008, “Territorios, prácticas rituales y demarcación del espacio en Tarapacá en el siglo XVI", en Boletín del Museo Chileno de Arte Precolombino, $13(2), 57-75$.

Santander, C.U., 2006, La migración peruana en el contexto del patrón de las corrientes migratorias en Chile: pasado, presente y futuro. Ponencia presentada en el Lasa Congress, 15-16 de marzo, San Juan, Puerto Rico.

Schiappacasse Cambiaso, P., 2008, "Segregación espacial y nichos étnicos de los migrantes internacionales en el Área Metropolitana de Santiago, en Revista de Geografia Norte Grande, 39: 21-38."

Segato, R.L., 2007, La nación y sus otros: Raza, etnicidad y diversidad religiosa en tiempos de Políticas de la Identidad. Prometeo. Buenos Aires.

Setién, M.L. y Acosta, E., 2011, "Cuidados y flujos migratorios feminizados surnorte y sur/sur: Negación de derechos y ciudadanía limitada”, en Revista Latina de Sociología, 1: 182-208. 
Stefoni, C. y Fernández, R., 2011, "Mujeres inmigrantes en el trabajo doméstico: entre el servilismo y los derechos", en Stefoni, C. (ed.) Mujeres inmigrantes en Chile ¿Mano de obra o trabajadoras con derecho?, pp. 43-72. Editorial de la Universidad Alberto Hurtado. Santiago de Chile.

Stefoni, C., 2002, "Mujeres inmigrantes peruanas en Chile", en Papeles de Población, 33, 118-145.

Stefoni, C., 2005, "Inmigrantes Transnacionales. La formación de comunidades y la transformación en ciudadanos", en Berg, U.D. y Paerregaard, K. (eds.), $E l$ quinto suyo. Transnacionalidad y formación diaspórica en la migración peruana, pp. 261-289. Instituto de Estudios Peruanos. Lima.

Stefoni, C., 2009, "Migración, género y servicio doméstico. Mujeres peruanas en Chile", en Valenzuela, M.E y Mora, C. (eds.), Trabajo doméstico: un largo camino hacia el trabajo decente, pp. 191-232. OIT. Santiago de Chile.

Stefoni, C., 2011, "Ley y política migratoria en Chile. La ambivalencia en la comprensión del migrante", en Feldman Bianco, B.; Rivera Sánchez, L.; Stefoni, C. y Villa Martínez, M.I. (comp.) La construcción social del sujeto migrante en América Latina. Prácticas, representaciones y categorias, pp. 79-110. CLACSOFLACSO-UAH. Quito.

Sutcliffe, B., 1996, Nacido en otra parte. Un ensayo sobre la migración internacional, el desarrollo y la equidad. Hegoa. Bilbao.

Tapia, M. y Ovando, C., 2013, "Los Andes tarapaqueños, nuevas espacialidades y movilidad fronteriza ¿barrera geográfica o espacio para la integración?”, en Núñez, A, Sánchez, R y Arenas, F. (eds.) Fronteras en movimiento e imaginarios geográficos. La Cordillera de los Andes como espacialidad socio-cultural, pp. 243-274. Instituto de Geografía, Pontificia Universidad Católica. Santiago de Chile.

Tapia, M. y Parella, S., 2015, "Las regiones fronterizas para el estudio de la migración y la circulación. Un análisis a partir de dos casos ilustrativos", en Guizardi, M. (ed). Las fronteras del Transnacionalismo. Límites y desbordes de la experiencia migrante en el centro y norte de Chile. Ocho Libros. Santiago de Chile.

Tapia, M. y Ramos, R., 2013, "Mujeres migrantes fronterizas en Tarapacá a principios del siglo XXI. El cruce de las fronteras y las redes de apoyo", en Polis, Revista Latinoamericana, 12(35), 229-257.

Tapia, M., 2012, "Frontera y migración en el norte de Chile a partir del análisis de los censos de población. Siglos XIX- XXI, en Revista de Geografía Norte Grande, 53: $177-198$

Tapia, M., 2013, "Migración y movilidad de los trabajadores fronterizos en Tarapacá durante el ciclo del nitrato, 1880-1930", en González, S. (comp.), La Sociedad del Salitre: Protagonistas, migraciones, cultura urbana y espacios públicos, pp. 163-194. Lom Ediciones. Santiago de Chile.

Thayer, E., 2011, “Trabajo y género: la condición social de inmigrante como referente para la definición de la identidad", en Stefoni, C. (ed.) Mujeres inmigrantes 
en Chile ¿Mano de obra o trabajadoras con derechos?, pp. 75-108. Editorial Universidad Alberto Hurtado. Santiago de Chile.

Tijoux, M.E., 2007, "Peruanas migrantes en Santiago. Un arte cotidiano de la lucha por la vida", en Polis, (18), 1-12.

Tijoux, M.E., 2011, “Negando al 'otro': el constante sufrimiento de los inmigrantes peruanos en Chile", en Stefoni, C. (Ed.) Mujeres inmigrantes en Chile ¿Mano de obra o trabajadoras con derecho?, pp. 15-42. Editorial de la Universidad Alberto Hurtado. Santiago de Chile.

Tijoux, M.E., 2013, “Las escuelas de la inmigración en la ciudad de Santiago: Elementos para una educación contra el racismo," en Polis, 12(35), 287-307.

Tijoux, M.E., 2014, Asentamientos, poblaciones y autoridades de Tarapacá, siglos XV y XVI, ca. 1400-1572, Tesis para optar al grado de Magíster en Historia. Universidad de Chile, Santiago de Chile.

Urbina, S., 2011, Sobre Espacialidad Incaica y Planificación Hispana: Hacia una Arqueología Colonial de Tarapacá, Siglos XV-XVII DC (Norte de Chile), en Márquez Belloni, F., Simposio Arqueología, Antropología e Historia. Simposio llevado a cabo en el $6^{\circ}$ Congreso Chileno de Antropología, pp.1992-2008. Universidad Austral. Valdivia.

Valdebenito, F. y Guizardi, M.L., 2014, “Las fronteras de la modernidad. El espacio Tacnoariqueño y la nacionalización del Norte Grande chileno, 1883-1929”, en Revista de Estudos Ibero-Americanos, 40(2): 277-303.

Valdebenito, F. y Guizardi, M.L., 2015, "Espacialidades migrantes. Una etnografía de la experiencia de mujeres peruanas en Arica, Chile", en Gazeta de Antropología, 31(1): s/n.

Vergara, J. I. y Gundermann, H., 2007, “El juego de las diferencias: de lo nacionalregional a lo regional-indígena: Una comparación entre Tarapacá y Los Lagos”, en Revista Austral Ciencias Sociales, (12), 31-56

Vergara, M., 2005, El trabajo de los extranjeros en Chile y en la I Región. Dirección Nacional del Trabajo. Santiago de Chile.

Vicuña, J.T.; Guizardi, M.L.; Pérez, C. y Rojas, T., 2015, “Características Económicas y sociodemográficas de la Región de Arica y Parinacota”, en Vicuña, J.T. y Rojas, T. (eds.), Migración internacional en Arica y Parinacota: Panoramas y tendencias de una región fronteriza,pp. 37-48. Editorial de la Universidad Alberto Hurtado. Santiago de Chile.

Wallerstein, I. y Balibar, E., 1991, Raza, nación y clase. IEPALA. Madrid. 


\section{RESUMEN CURRICULAR DE LOS AUTORES}

\section{Menara Lube Guizardi}

Es Cientista Social y posgraduada en Ciencias Humanas y Desarrollo Regional por la Universidade Federal do Espírito Santo (UFES, Brasil); máster en Estudios Latinoamericanos y Doctora en Antropología Social, ambos por la Universidad Autónoma de Madrid (UAM, España). Actualmente desempeña como investigadora postdoctoral del Instituto de Altos Estudios Sociales de la Universidad Nacional de San Martín (IDAESUNSAM, Argentina) y como Investigadora Asociada de la Universidad de Tarapacá (Arica, Chile). Su libro más reciente es Capoeira. Etnografía de una historia transnacional entre Brasil y Madrid, publicado por las Ediciones de la Universidad Alberto Hurtado (Santiago, Chile) en 2017. Dirección electrónica: menaraguizardi@yahoo.com.br

\section{Esteban Nazal Moreno}

Es Licenciado en Antropología Social en la Universidad de Chile (Santiago, Chile). Ha desarrollado investigaciones sobre los procesos de dependencia económica y crisis políticas en contextos centro-americanos. Actualmente ejerce como profesor colaborador del Departamento de Antropología de la Universidad Alberto Hurtado (Chile). Su artículo más reciente es "Genealogías teóricas del transnacionalismo migrante. Apuntes para una revisión antropológica crítica", publicado en 2017 por la Revista Papeles de Trabajo (Rosario, Argentina).

Dirección electrónica: enazalmoreno@gmail.com

\section{Felipe Valdebenito Tamborino}

Es Antropólogo Social por la Universidad de Tarapacá (Arica, Chile). Actualmente es becario doctoral de la Comisión Nacional de Investigación Científica y Tecnológica de Chile (CONICYT) y cursa el Programa de Doctorado en Antropología que imparten en conjunto la Universidad Católica del Norte y la Universidad de Tarapacá en Chile. Desarrolla investigaciones sobre movilidad y espacialidad en zonas de frontera, migración transnacional en ámbitos urbanos, y migraciones internas e internacionales asociadas con los ciclos mineros del norte chileno. Actualmente ejerce como profesor del Departamento de Antropología en la Universidad de Tarapacá (Arica, Chile). Su última publicación es "Movilidad y espacialidad en la (trans)frontera Tacno-ariqueña. Sur peruano y norte chileno" en 
la Revista de Estudios Transfronterizos Si Somos Americanos (Universidad Arturo Pratt, 2017).

Dirección electrónica: valdeb.felipe@gmail.com

\section{Eleonora López Contreras}

Es Licenciada en Sociología por la Universidad Nacional Autónoma de México (DF, México). Actualmente es becaria de magister por la Agencia de Cooperación Internacional: Ministerio de Relaciones Exteriores (Chile) y Secretaria de Relaciones Exteriores (México) cursando el programa de Ciencias Sociales con Mención en Sociología de la Modernización de la Universidad de Chile. Es integrante del Laboratorio Transdisciplinar de Prácticas Sociales y Subjetividad (LaPSoS) de la Universidad de Chile, asimismo es investigadora responsable del proyecto "Estudio exploratoriodescriptivo de las múltiples realidades del colectivo inmigrante haitiano" y coordinadora del "Núcleo de estudios transdisciplinares sobre migración haitiana" ambos financiados por la Facultad de Ciencias Sociales de la Universidad de Chile. Su publicación más reciente es "Explorando modelos para explicar la participación individual en protestas en el Chile contemporáneo" publicado en 2017 por la Revista de Sociología (Universidad de Chile).

Dirección electrónica:eleonoralopezcontreras@gmail.com

Artículo recibido el 15 de junio de 2015 y aprobado el 3 de agosto de 2017. 